GA-A16270

UC-77

\title{
STRENGTH OF NONUNIFORMLY OXIDIZED PGX GRAPHITE
}

\author{
by \\ R. J. PRICE and L. A. BEAVAN
}

\author{
Prepared under \\ Contract DE-AT03-76ET35301 \\ for the San Francisco Operations Office \\ Department of Energy
}

PIrab tocument is

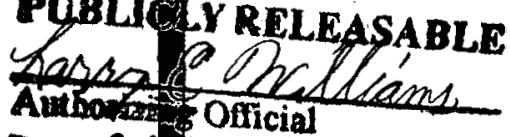

Dim 0 Official

Dom 064262003

\section{GENERAL ATOMIC PROJECT 7400 DATE PUBLISHED: MAY 1981}

DISTRIBUTION OF THIS DOCIIKENT IS UMIHTTE

\section{GENERAL ATOMIC COMPANY}




\section{DISCLAIMER}

This report was prepared as an account of work sponsored by an agency of the United States Government. Neither the United States Government nor any agency Thereof, nor any of their employees, makes any warranty, express or implied, or assumes any legal liability or responsibility for the accuracy, completeness, or usefulness of any information, apparatus, product, or process disclosed, or represents that its use would not infringe privately owned rights. Reference herein to any specific commercial product, process, or service by trade name, trademark, manufacturer, or otherwise does not necessarily constitute or imply its endorsement, recommendation, or favoring by the United States Government or any agency thereof. The views and opinions of authors expressed herein do not necessarily state or reflect those of the United States Government or any agency thereof. 


\section{DISCLAIMER}

Portions of this document may be illegible in electronic image products. Images are produced from the best available original document. 

Flexural and tensile tests were performed on PGX graphite oxidized to produce a steep surface oxidation gradient. Companion tensile specimens were oxidized under different conditions to produce uniform oxidation throughout the specimen, and their tensile strength and Young's modulus were measured. The flexural strength, flexural elastic modulus, and tensile strength were reduced much less by surface oxidation than by uniform oxidation. The test data were in good agreement with a simple linear elastic model in which Young's modulus at any point is a function of oxidation burnoff, and the strain at failure is independent of oxidation. The unoxidized interior of the specimens appears unaffected by the surface burnoff and remains able to fulfill its load-bearing function. 
CONTENTS

ABSTRACT . . . . . . . . . . . . . . . . . . . . .

1. INTRODUCTION . . . . . . . . . . . . . . . . . . . . 1

2. MATERIAL ......................... . . . . . 2

3. EXPERIMENTAL METHODS ..................... . . . 6

3.1. Oxidation . . . . . . . . . . . . . . 6

3.2. Uniform Oxidation Tensile Tests . . . . . . . . . . 6

3.3. Surface Oxidation Flexural and Tensile Tests . . . . . . 8

3.4. Oxidation Profiles . . . . . . . . . . . . . . . 8

4. RESULTS . . . . . . . . . . . . . . . . . . . 11

4.1. Uniform Oxidation: Tensile Properties . . . . . . . . . 11

4.2. Nonuniform Oxidation: Profiles . . . . . . . . . 17

4.3. Nonuniform Oxidation: Flexural Tests . . . . . . . 17

4.4. Nonuniform Oxidation: Tensile Tests.......... 26

5. ANALYSIS . . . . . . . . . . . . . . . . . . . 31

5.1. Flexural Tests................... . . 31

5.2. Tensile Tests . . . . . . . . . . . . . . . 34

6. SUMMARY AND CONCLUSIONS . . . . . . . . . . . . . . . . 41

REFERENCES . . . . . . . . . . . . . . . . . . . . . . 4 43

\section{FIGURES}

1. Location of slab $4 / 5$ in parent $\log$ of PGX graphite . . . . . 4

2. Sectioning plan for slab 4/5, PGX graphite . . . . . . . . 5

3. Blocks before oxidation and location of bar for tensile testing, beams for bend testing, and cores for oxidation profile testing in oxidized blocks . . . . . . . . . . . 7

4. Schematic illustration of four-point bending fixture . . . . 10

5. Dependence of strength and Young's modulus on burnoff in uniformly oxidized graphite . . . . . . . . . . . . . 12 
FIGURES (Continued)

6. Dependence of strength and Young's modulus on burnoff in uniformily oxidized PGX graphite, $\log 6484-112$. . . . . . . 14

7. Scanning electron micrographs of fracture surfaces of uniformly oxidized PGX graphite: (a) $\log 6484-112$, (b) $\log 6484-138$. . . . . . . . . . . . . . . . . . . . . . . 15

8. Dependence of tensile strength and Young's modulus on burnoff in uniformly oxidized PGX graphite, $\log 6848-138$. . . 16

9. Oxidation profiles from preliminary surface oxidation tests on PGX graphite; 100 hours oxidation . . . . . . . . 18

10. Surface oxidation profile for PGX graphite, $\log 6484$,

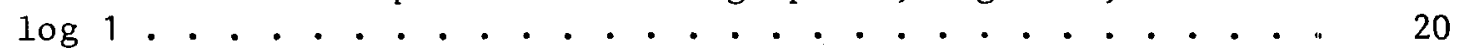

11. Surface oxidation profile for PGX graphite, $\log 6484-112$,

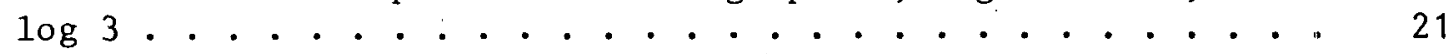

12. Surface oxidation profile for PGX graphite, $\log 6484-112$, $\log 8$. . . . . . . . . . . . . . . . . 22

13. Surface oxidation profile for PGX graphite, $\log 6484-112$, $\log 11$. . . . . . . . . . . . . . . . . . . 23

14. Surface oxidation profile for PGX graphite, $\log 6484-112$, $\log 12$. . . . . . . . . . . . . . . . . . . . 24

15. Change in apparent modulus of rupture versus burnoff depth in surface-oxidized PGX graphite . . . . . . . . . . 28

16. Observed flexural strength versus predicted flexural strength for surface-oxidized PGX graphite . . . . . . . . . . 36

17. Observed beam deflection versus predicted beam deflection for surface-oxidized PGX graphite . . . . . . . . . . . . 37

18. Observed tensile strength versus predicted tensile strength for surface-oxidized PGX graphite . . . . . . . .

\section{TABLES}

1. Impurity content of PGX graphite $(\log 6484-112)$. . . . . . . . 3

2. Oxidation conditions for oxidation profile/strength tests on PGX graphite $(\log 6484-112)$. . . . . . . . . . . . . . . . . 19

3. Flexural properties of PGX graphite: unoxidized controls . . . 25

4. Flexural properties of surface-oxidized PGX graphite . . . . . . 27

5. Tensile strength of PGX graphite: unoxidized controls . . . . 29 


\section{TABLES (Continued)}

6. Tensile strength of surface-oxidized bars of PGX . . . . . . . . 30

7. Comparison of observed and calculated flexural behavior of surface-oxidized PGX graphite . . . . . . . . . . . . 35

8. Comparison of observed and calculated tensile strength of surface-oxidized PGX graphite. . . . . . . . . . . . . . . . 


\section{INTRODUCTION ${ }^{*}$}

The core support structures of high-temperature gas-cooled nuclear reactors (HTGRs) are made from graphite. Accidental steam ingress into the helium coolant can lead to slow oxidation of the graphite components. Under HTGR operating conditions, oxidation is expected to be limited to the surface (Ref. 1). The effects of uniform oxidation on the mechanical properties of graphite are severe (with uniform oxidation, each 1\% burnoff reduces both the tensile strength and Young's modulus by $5 \%$ to 10\%), and it is important to verify experimentally that surface oxidation leaves the interior of the graphite unchanged and able to fulfill its load-bearing function. In particular, the possibility that cracks originating in the oxidized surface layer could propagate into the interior and cause unexpected weakening needs to be explored.

This report describes a series of flexural and tensile tests on PGX graphite (the grade used for the core support blocks of the Fort St. Vrain HTGR) oxidized to produce a steep surface oxidation gradient. The data were analyzed according to a simple linear elastic model in which Young's modulus at any point is a function of the local oxidation burnoff. Companion tensile specimens were oxidized under different conditions to produce uniform oxidation throughout the specimen, and their Young's modulus and tensile strength were measured.

\footnotetext{
*A portion of this work was presented at the $33 \mathrm{rd}$ Pacific Coast Regional Meeting of the American Ceramic Society, October 26-29, 1980, San Francisco, California.
} 


\section{MATERIAL}

Test samples were taken from log 6484-112 of PGX graphite (Union Carbide Corporation, manufacturer's log number 8D5-3). The parent 109 measured $1.83 \mathrm{~m}$ long $\times 1.14 \mathrm{~m}$ diameter (72 in. $\times 45$ in.) and had a bulk density of $1.78 \mathrm{Mg} / \mathrm{m}^{3}$. The impurity content of coupon samples is shown in Table 1. The test specimens were taken from a quadrant of slab No. 4/5 [305 mm (12 in.) deep]; the location in the parent $\log$ is shown j.n Fig. 1. The slab was cut into numbered blocks measuring $63 \mathrm{~mm} \times 76 \mathrm{~mm} \times 254 \mathrm{~mm}$ (2.5 in. $x 3$ in. $x 10$ in.), as shown in Fig. 2. Blocks used in preliminary tests to establish suitable oxidation conditions were further cut into four specimens measuring $51 \mathrm{~mm} \times 63 \mathrm{~mm} \times 76 \mathrm{~mm}$ (2 in. x 2.5 in. x 3 in.), which were identified by the block number followed by the subscript A, B, C, or D. Companion tensile specimens for uniform oxidation tests, measuring $31.8 \mathrm{~mm}$ long $\times 6.3 \mathrm{~mm}$ diameter ( 1.25 in. $\times 0.25$ in.), were taken from slab 6, sections $\mathrm{AE}$ and $\mathrm{AY}$ in the quadrant directly opposite the quadrant sampled for the nonuniform oxidation tests. 
TABLE 1

IMPURITY CONTENT OF PGX GRAPHITE (LOG 6484-112)

\begin{tabular}{l|r}
\hline Impurity & $\begin{array}{c}\text { Concentration } \\
\text { (ppm) }\end{array}$ \\
\hline Total ash & 6400 \\
Sulfur & 640 \\
Iron & 3000 \\
Aluminum & 230 \\
Barium & 100 \\
Calcium & 250 \\
Copper & 140 \\
Magnesium & 75 \\
Manganese & 75 \\
Nicke1 & 75 \\
Silicon & 100 \\
Vanadium & 50 \\
Titanium & 50 \\
Zinc & 30 \\
\hline
\end{tabular}




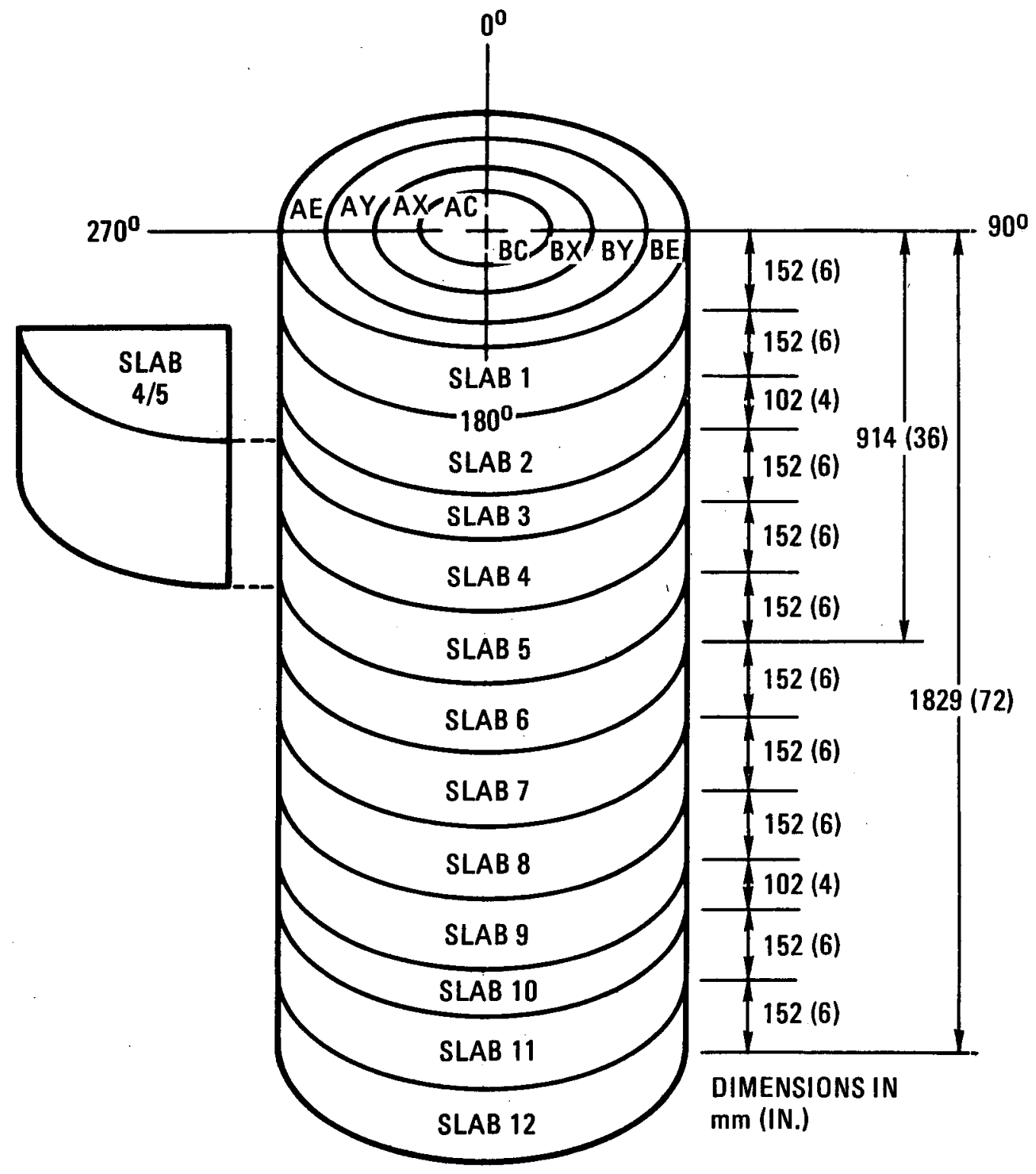

Fig. 1. Location of slab $4 / 5$ in parent $\log$ of PGX graphite 


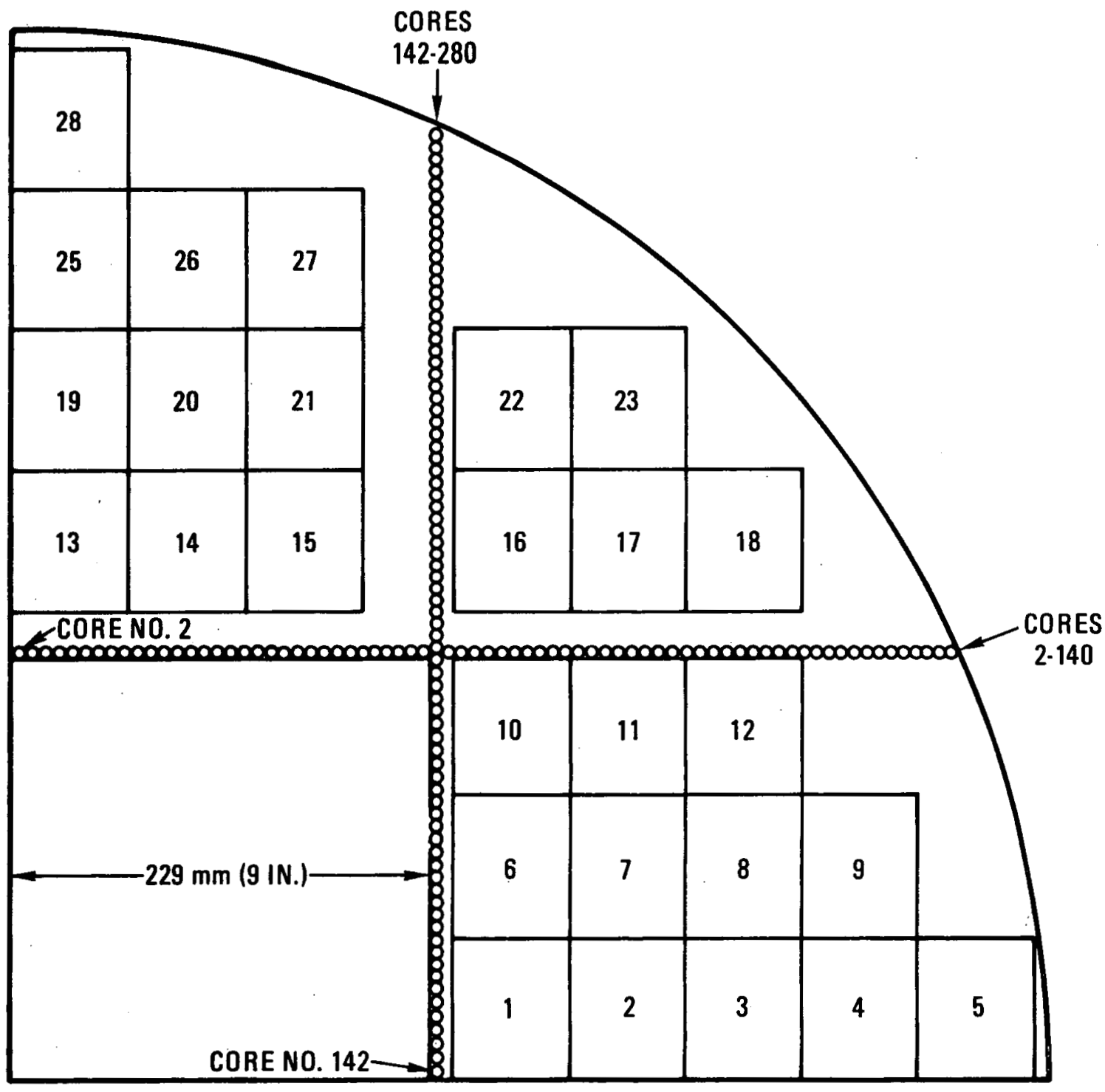

Fig. 2. Sectioning plan for slab 4/5, PGX graphite 


\section{EXPERIMENTAL METHODS}

\subsection{OXIDATION}

The specimens were oxidized in silica furnace tubes in flowing helium containing hydrogen and water vapor. The tensile specimens for uni:form oxidation tests were supported on the edges of $4.76 \mathrm{~mm}(0.188 \mathrm{in}$.$) wide$ slots in H-451 graphite support trays. The blocks for surface oxidation were machined to the form shown in Fig. 3a. 'the central recess on the top and bottom faces was exposed to oxidation, while the other surfaces were masked by holders made from a purer, less reactive graphite (Great lakes Carbon Corporation grade $\mathrm{H}-451$ ). In spite of the masking, the reaction rate of the exposed PGX graphite was high enough to cause considerable depletion of the oxidant in the gas stream. This resulted in the two exposed faces of the PGX block receiving different burnoffs.

\subsection{UNIFORM OXIDATION TENSILE TESTS}

After oxidation, the PGX cylinders subjected to uniform oxidation were trimmed at each end, reducing the cylinder length from $31 \mathrm{~mm}$ (1.25 in.) to $23 \mathrm{~mm}$ (0.90 in.). Each cylindrical specimen was epoxied to aluminum end pieces in an alignment $j i g$ and pulled in a self-aligning precision load train. The tensile load was increased linearly to $6.9 \mathrm{MPa}$ (1000 ps:i), lowered to $0.69 \mathrm{MPa}$ (100 psi), and increased again until failure. Many oxidized specimens failed during the initial loading to $6.9 \mathrm{MPa}$ (1000 psi). Strain was measured utilizing a clip-on extensometer over a $12.7 \mathrm{~mm}$ (0.5 in.) gage length. Tensile failures within $2 \mathrm{~mm}(0.1 \mathrm{in.})$ of the glued ends of the specimen were discarded in calculating tensile strengths. 


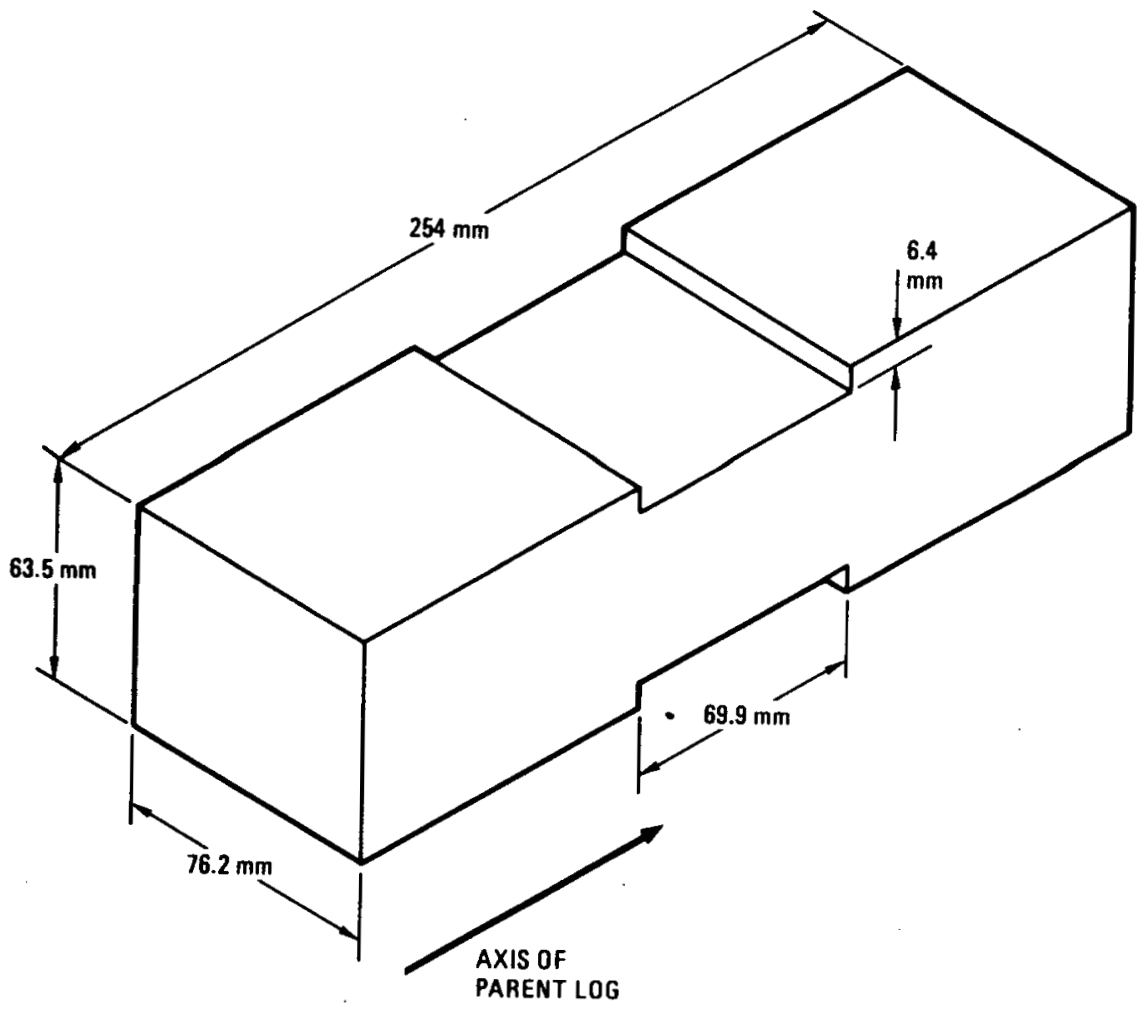

(a)

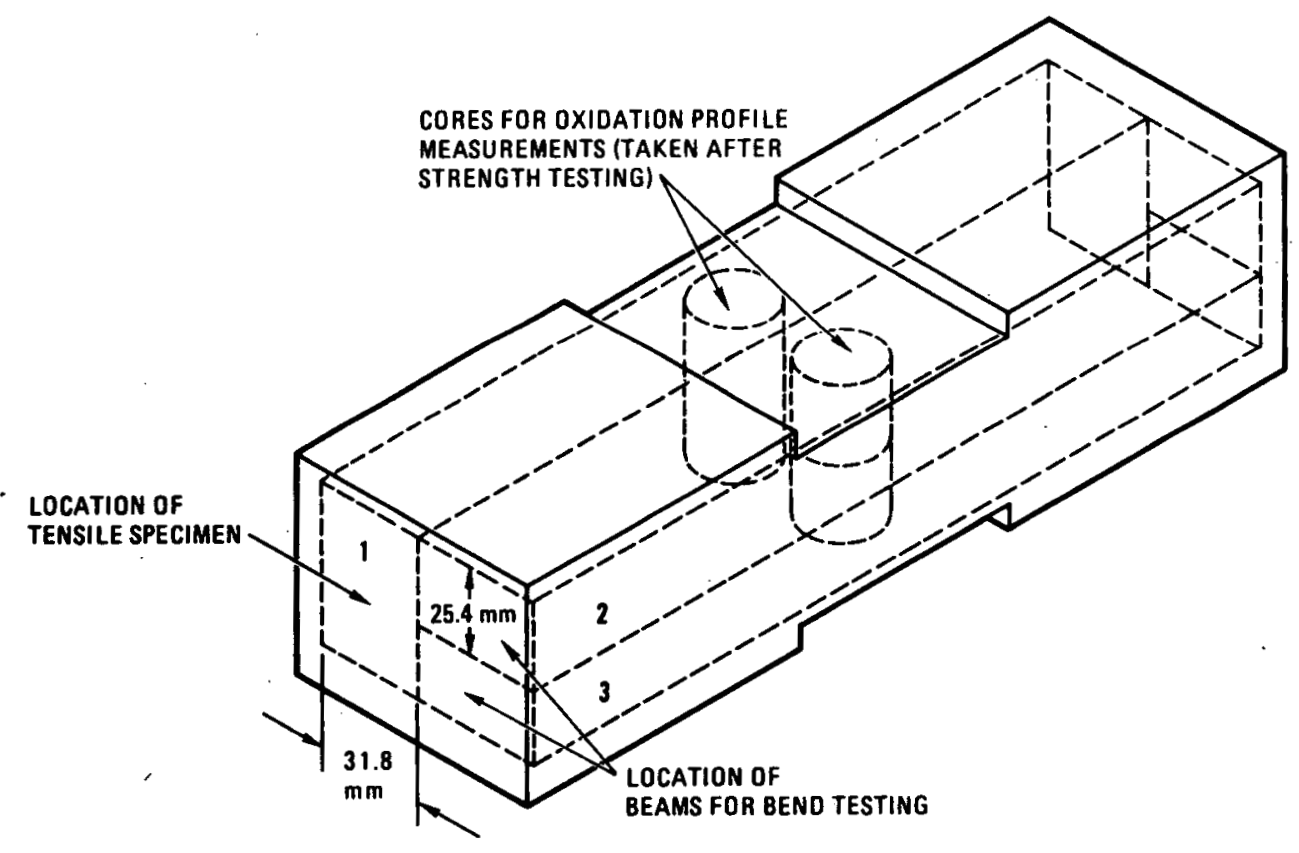

(b)

Fig. 3. (a) Blocks before oxidation; (b) location of bar for tensile testing, beams for bend testing, and cores for oxidation profile testing in oxidized blocks 


\subsection{SURFACE OXIDATION FLEXURAL AND TENSILE TESTS}

After oxidation, the PGX blocks were cut into a bar with a rectangular cross section [31.8 $\mathrm{mm} \times 50.8 \mathrm{~mm}$ (1.25 in. $\times 2.00$ in.)] for tensile testing and two beams with a $25.4 \mathrm{~mm}$ ( 1 in.) square cross section for flexural testing, as shown in Fig. 3b. The machined specimens had a constant cross section along their length, but an oxidized zone occupied the central $70 \mathrm{~mm}$ (2.75 in.) of the specimens. One face of the flexural specimens contained the oxidized zone, whereas two opposite faces of the tensile bar were oxidized. Control specimens were machined from unoxidized blocks.

The flexural specimens were tested in four-point loading in an Instron testing machine. The bending fixture is shown schematically in Fig. 4. The loading bars were equally spaced $76 \mathrm{~mm}$ ( $3 \mathrm{in.}$ ) apart, and the center point deflection was monitored with a deflectometer finger. The crosshead speed was $0.13 \mathrm{~mm} / \mathrm{min}(0.005 \mathrm{in.} / \mathrm{min})$. The specimen was positioned so that the central oxidized zone occupied the space between the two central loading bars, while the bars themselves contacted unoxidized graphite. This procedure avoided crumbling at the contact points, even when the beams were tested with the oxidized face in compression.

The tensile bars were tested by cementing their ends with epoxy cement to metal end caps attached to short lengths of chain, and testing to failure in a Tinius-01sen machine. This specimen geometry is far from ideal, and fractures tended to take place preferentially near the cemented joints (although not through the cement). However, the technique is adequate to detect significant strength differences between oxidized and unoxidized specimens.

\subsection{OXIDATION PROFILES}

After completing the mechanical tests, cylindrical cores $24 \mathrm{~mm}$ (0.96 in.) in diameter were machined from the oxidized zone, as shown in 
Fig. 3b, taking care not to damage the fragile oxidized surface.

Successive layers $0.25 \mathrm{~mm}$ (0.01 in.) thick were machined from the core, starting at the oxidized face. After each cut the core was weighed to an accuracy of $0.0001 \mathrm{~g}$ and the height was measured to an accuracy of $0.0025 \mathrm{~mm}$ (0.0001 in.), using a measuring jig and plunger designed to ensure reproducible positioning of the core in the measuring jig. The oxidation profile was calculated from the difference between the density of each successive layer and the density of the unoxidized block. 
TO LOAD CELL

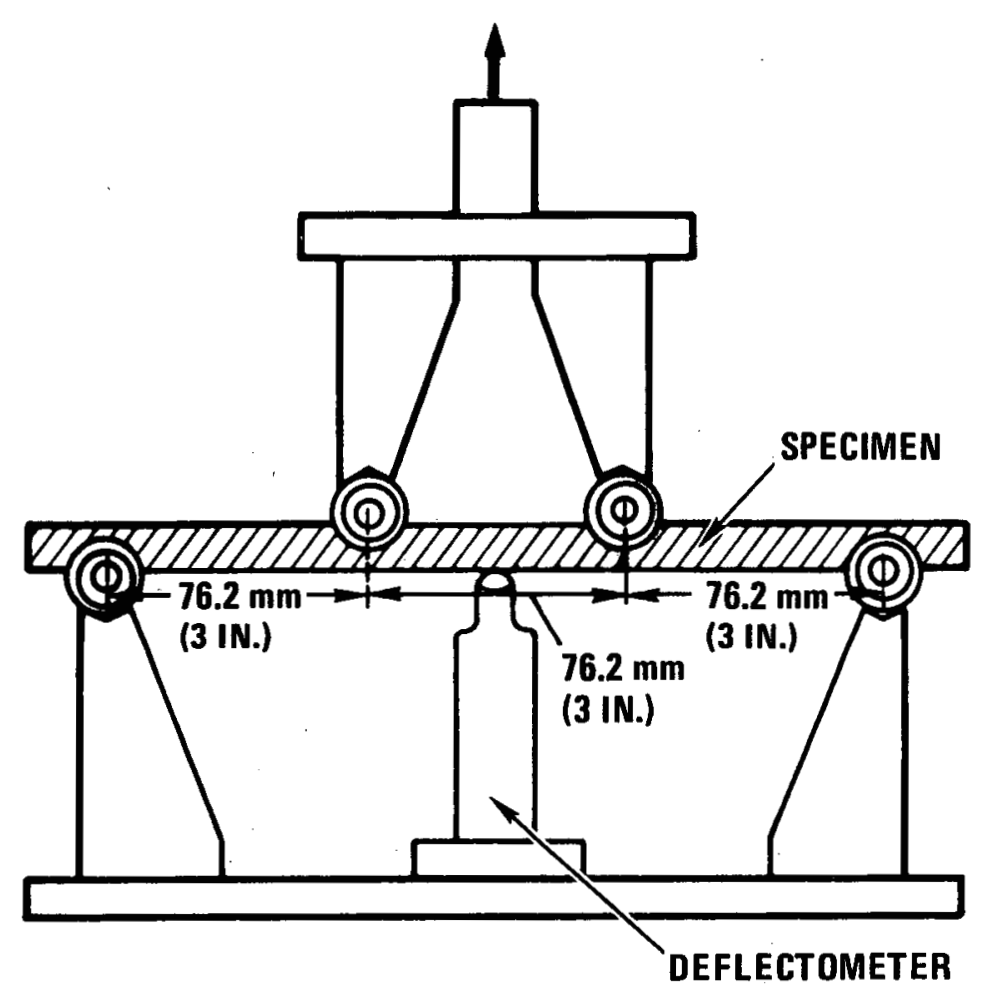

Fig. 4. Schematic illustration of four-point bending fixture 


\section{RESULTS}

\subsection{UNIFORM OXIDATION: TENSILE PROPERTIES}

Previous work has shown that uniform ${ }^{*}$ oxidation sharply reduces both the mechanical strength and Young's modulus of graphite (Refs. 2-7). The fractional reductions in strength and modulus are similar, leaving the strain to failure almost unchanged. The reduction is shown schematically in Fig. 5. The change in strength ( $S$ ) or Young's modulus (E) as a function of the fractional oxidation burnoff (y) can be represented either by the equation

$$
\frac{S}{S_{0}}=\frac{E}{E_{0}}=(1-y)^{m}
$$

or by the equation

$$
\frac{S}{S_{0}}=\frac{E}{E_{0}}=\exp (-y m)
$$

where the subscript 0 indicates the unoxidized state. As shown in Fig. 5, over the range of engineering interest there is very little difference between the relationships represented by Eqs. 1 and 2 , although Eq. 1 would provide the more conservative values for a given $\mathrm{m}$.

The exponent $m$ is an index of the rate of decline of strength with oxidation and ranges in value between 4 and 12 . The m-value depends on the

*In this context, "uniform" oxidation means the absence of a pronounced gradient in oxidation with depth below the surface. Strictly speaking, graphite oxidation is always heterogeneous because attack is concentrated at catalytic impurities and active sites. 


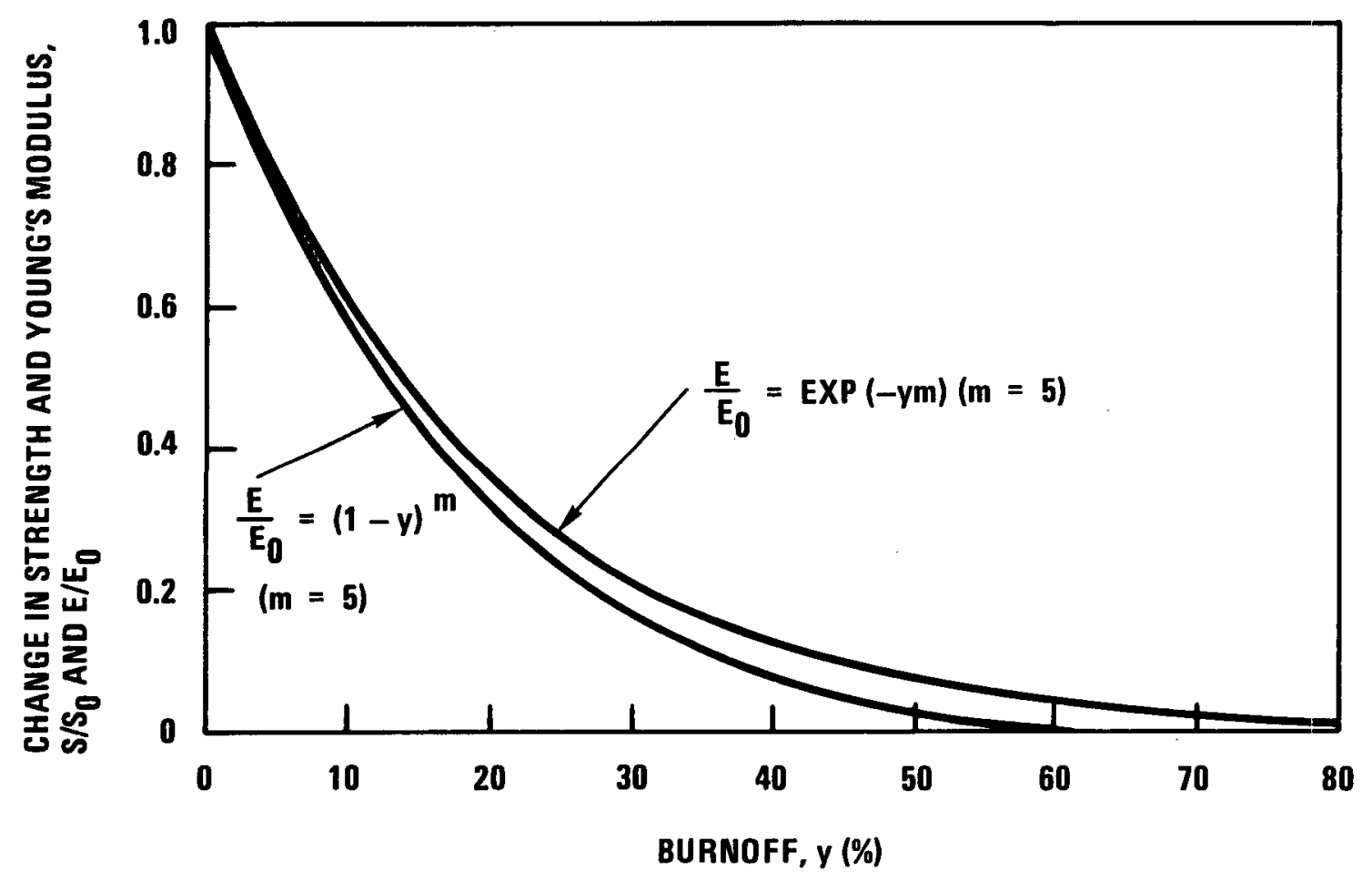

Fig. 5. Dependence of strength and Young's modulus on burnoff in uniformily oxidized graphite (schematic) 
morphology of the porosity resulting from oxidation and is affected by the nature and dispersion of catalytic impurities, the rate of reaction, and the presence of gamma radiation. Highly localized catalytic attack (pitting or "worm-holing"), high reaction rates, and a gamma field tend to be associated with low m-values. It is not possible to assign a unique m-value that characterizes the oxidation of a particular graphite grade under all conditions. In the present experiments there is an additional problem in that the pitting morphology in the surface-oxidized blocks, where a high reaction rate was used, was different from that of the uniformly oxidized companion specimens, which were oxidized at a much lower rate.

The uniformly oxidized tensile specimens were oxidized at $700^{\circ} \mathrm{C}$ in an atmosphere of flowing helium containing $4000 \mathrm{~Pa}$ hydrogen and $400 \mathrm{~Pa}$ water vapor. To achieve a range of burnoffs, oxidation times were varied from 2 to 100 days. The decrease in Young's modulus and tensile strength of the specimens from $\log 6484-112$ (companions to the surface-oxidized blocks) is shown as a function of burnoff in Fig. 6. The data can be represented by Eq. 1 or 2 with $m=10$. Micrographic examination of the fracture surfaces (Fig. 7a) showed that oxidation was not highly localized and the oxidation morphology was typified by "fluffy"-appearing pores. This appearance was markedly different from the surface-oxidized blocks, where oxidation was more localized and pitting was evident. The latter oxidation morphology was much closer to that seen in tensile specimens from a different log of PGX graphite ( $\log 6484-138$ ), which were oxidized under the same condition but which had a different "mix" of catalytic impurities (Ref. 8). Micrographs from oxidized specimens from $\log 6484-138$ are shown in Fig. 7b, and the measured decrease in strength and Young's modulus as a function of burnoff is shown in Fig. 8. In this case the data can be fit to Eq. 1 or 2 with $m=5$. Because of the very slow reaction rates that must be used to achieve quasi-uniform oxidation, the data in Figs. 6 and 8 do not extend beyond about $9 \%$ burnoff. However, data in the literature indicate that the trend represented by Eqs. 1 and 2 continues to at least $40 \%$ burnoff (Refs. 5, 7). 


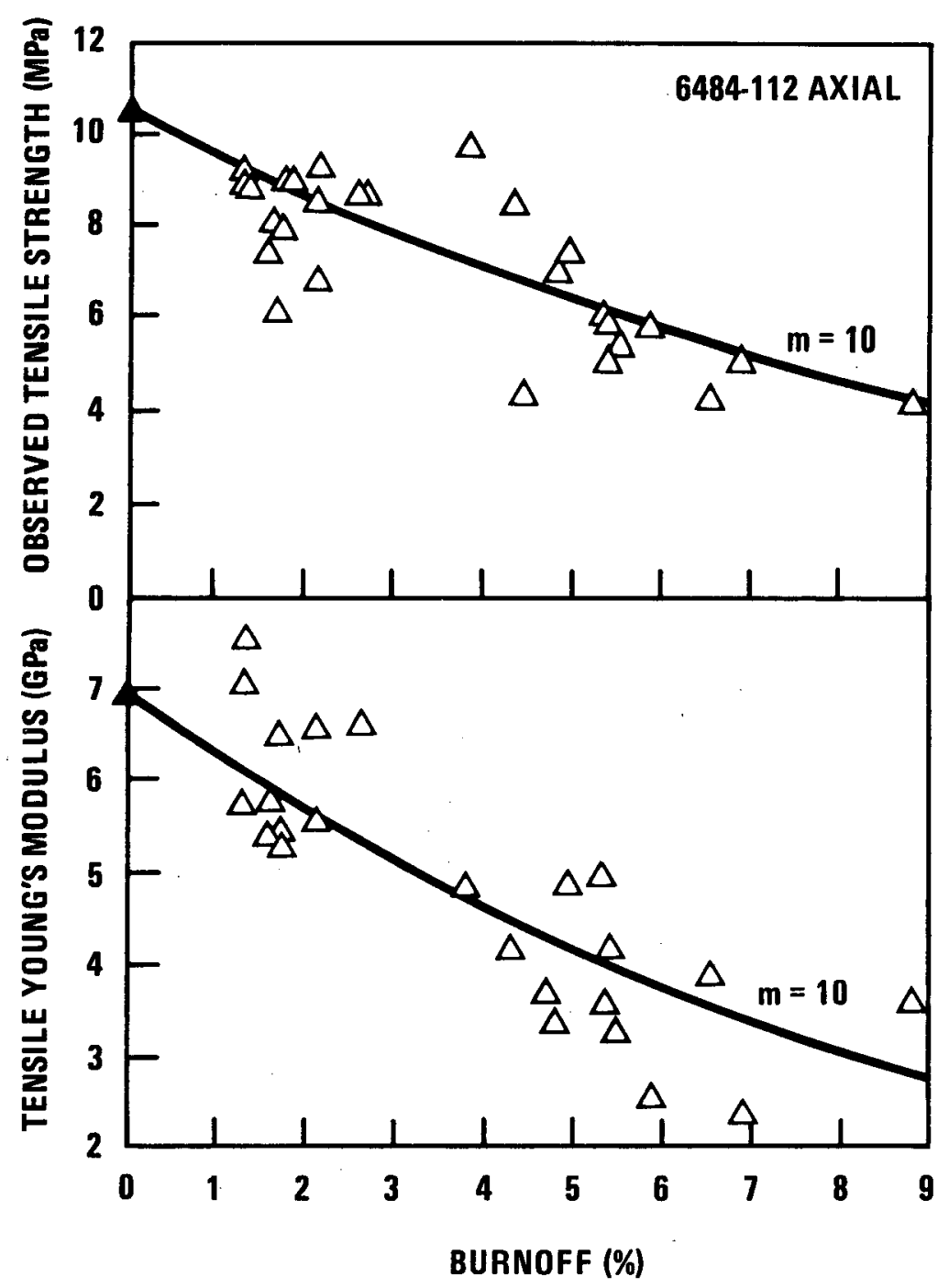

Fig. 6. Dependence of strength and Young's modulus on burnoff in uniformily oxidized PGX graphite, log 6484-112 

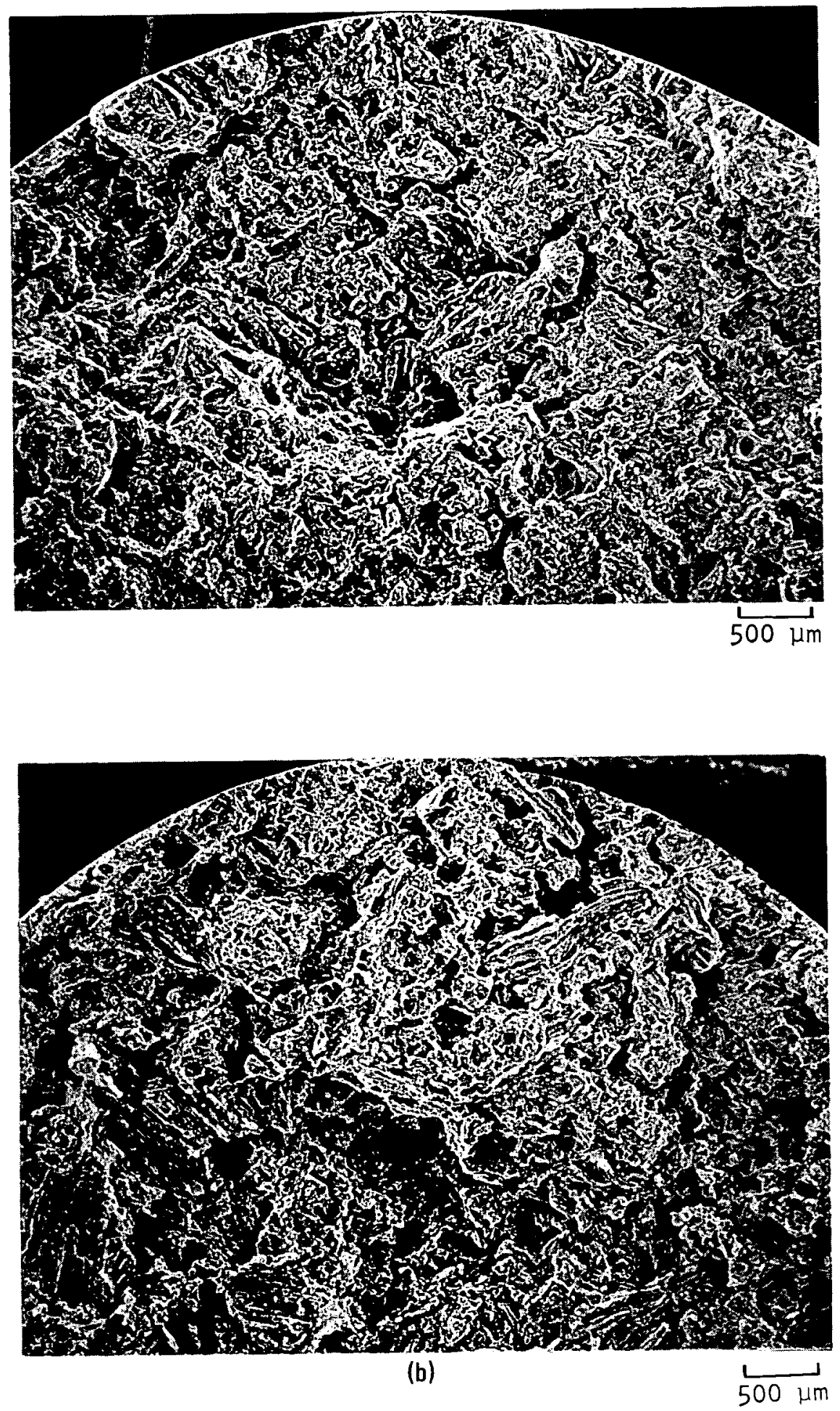

Fig. 7. Scanning electorn micrographs of fracture surfaces of uniformly oxidized PGX graphite: (a) $\log 6484-112$, (b) $\log 6484-138$ 


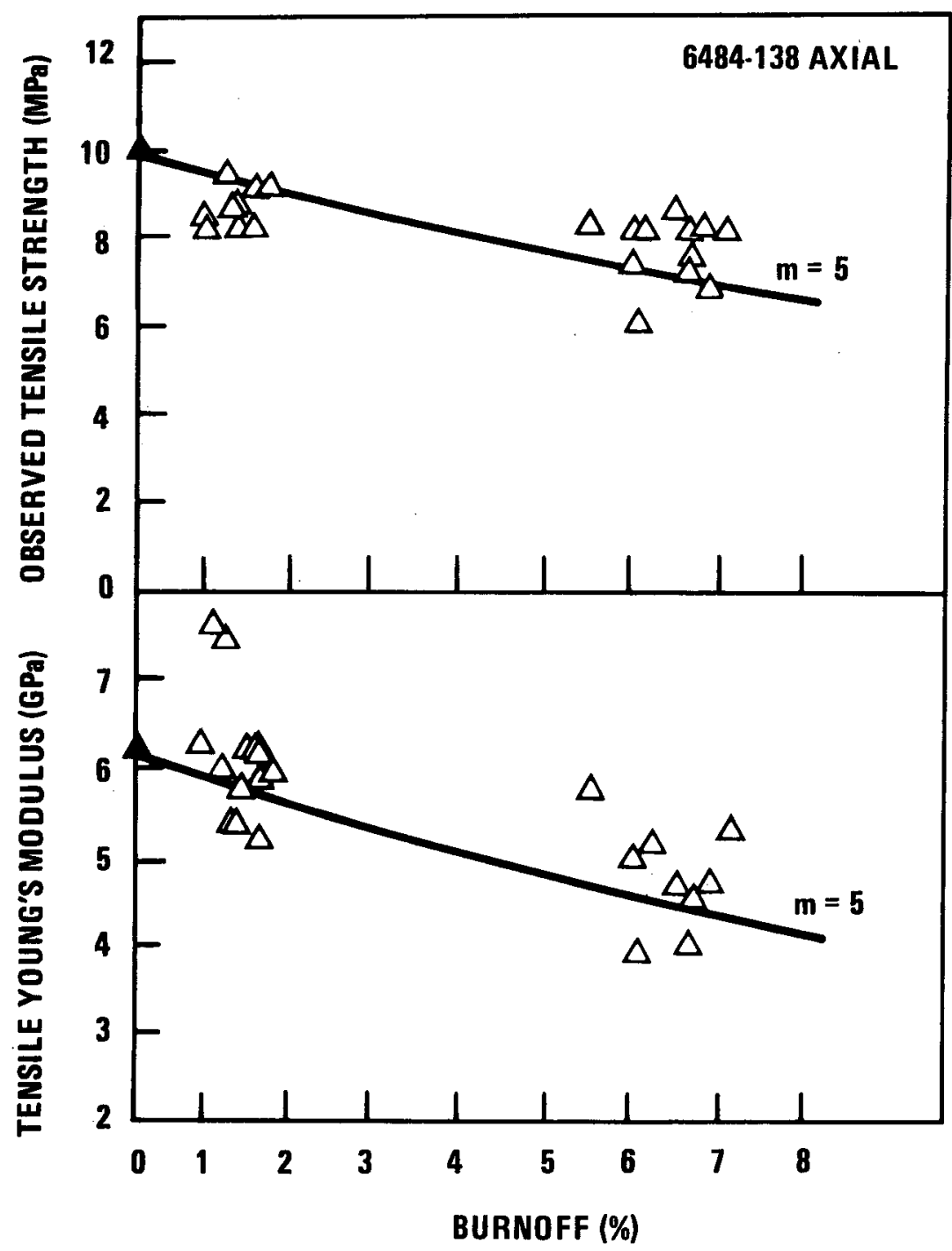

Fig. 8. Dependence of tensile strength and Young's modulus on burnoff in uniformly oxidized PGX graphite, $\log 6484-138$ 


\subsection{NONUNIFORM OXIDATION: PROFILES}

The first preliminary oxidation run on partial blocks of PGX graphite was conducted at $950^{\circ} \mathrm{C}$ in an atmosphere of $3000 \mathrm{~Pa}$ Hydrogen and $300 \mathrm{~Pa}$ water vapor for 4 hours. Oxidation during this run was negligible. For the second preliminary test, the oxidation conditions were changed to $900^{\circ} \mathrm{C}$, $4000 \mathrm{~Pa}$ hydrogen, $400 \mathrm{~Pa}$ water vapor, and 100 hours. The resulting oxidation profiles are shown in Fig. 9. These conditions caused a steep burnoff profile, declining from about $50 \%$ at the surface to $10 \%$ to $20 \%$ at a depth of $1 \mathrm{~mm}$ ( $0.05 \mathrm{in.})$ and less than $5 \%$ at a depth of $2 \mathrm{~mm}(0.1 \mathrm{in.})$. No anomalous burnoff profiles were seen.

Having established suitable oxidation conditions, six full-sized blocks (Fig. 3) were oxidized at $900^{\circ} \mathrm{C}$ in flowing helium containing $4000 \mathrm{~Pa}$ hydrogen and $400 \mathrm{~Pa}$ water vapor. Three blocks were oxidized for 100 hours and three blocks for 200 hours. The percent weight losses are shown in Table 2. The oxidation profiles (measured on cores taken after completion of the mechanical tests) are shown in Figs. 10 through 14 . Because of oxidant depletion and limited gas mixing in the oxidation furnace, the burnoff profiles on the opposite faces of the blocks were different, as indicated by the differences between the profiles for the two beam specimens (Figs. 10 through 14). However, data from two duplicate cores taken from the same beam were in good agreement. The burnoff depths (arbitrarily defined as the depth of the zone where the graphite density is less than $95 \%$ of its unoxidized value) varied from 0.8 to $3.3 \mathrm{~mm}$ ( 0.03 to $0.13 \mathrm{in.}$ ).

\subsection{NONUNIFORM OXIDATION: FLEXURAL TESTS}

Base-line flexural tests were performed on 16 unoxidized control specimens; the data are shown in Table 3. The average modulus of rupture (nominal outer fiber stress at fracture calculated from elastic beam theory) was 12.1 MPa (1752 psi), and the apparent Young's modulus (calculated from the load and center span deflection at fracture) was $4.1 \mathrm{GPa}\left(6.0 \times 10^{5} \mathrm{psi}\right)$. 

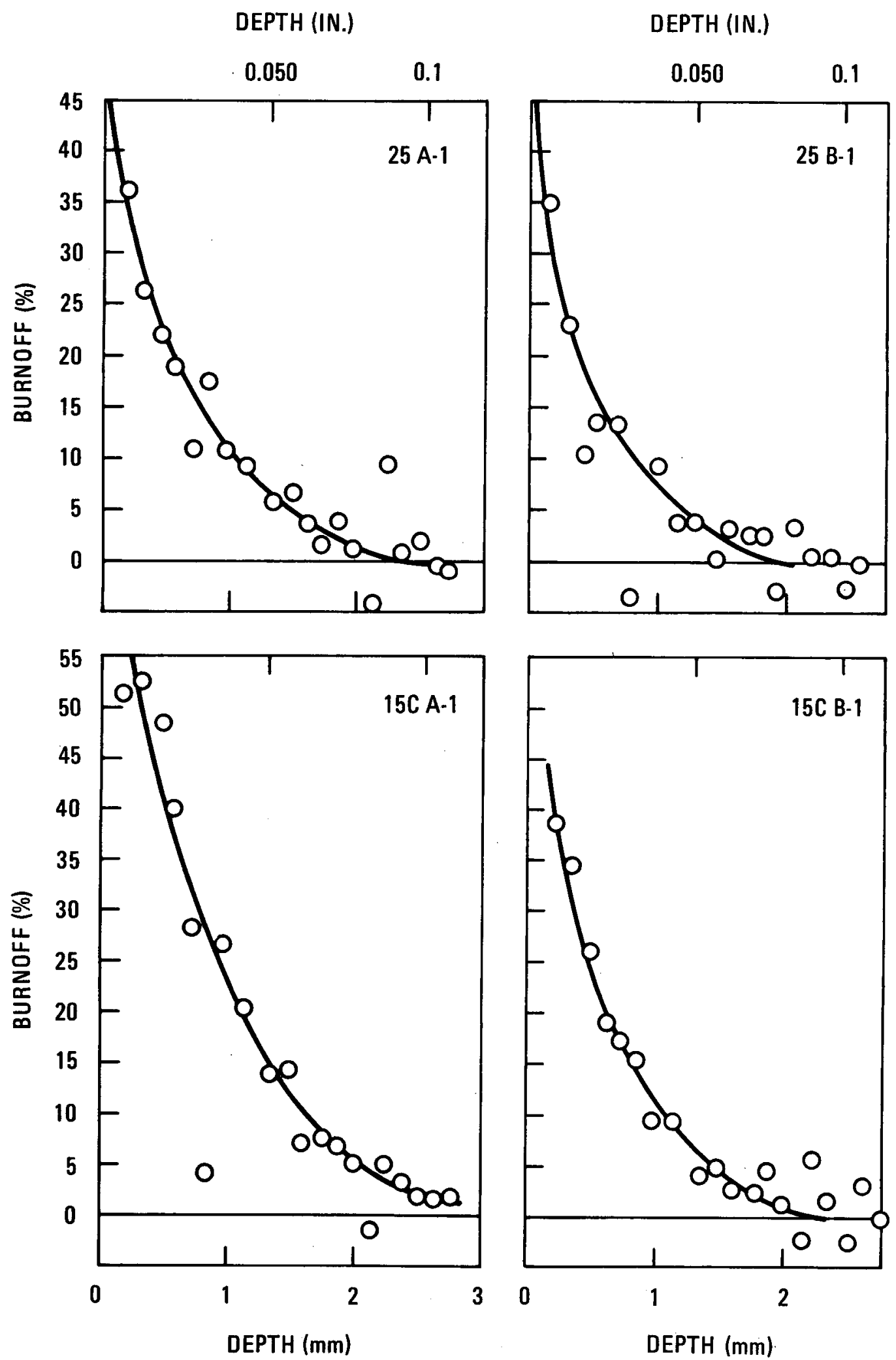

Fig. 9. Oxidation profiles from preliminary surface oxidation tests on PGX graphite; 100 hours oxidation 
TABLE 2

OXIDATION CONDITIONS FOR OXIDATION PROFILE/STRENGTH TESTS ON PGX GRAPHITE (Log 6484-112)

\begin{tabular}{c|c|c|c|c|c|c}
\hline \multirow{2}{*}{$\begin{array}{c}\text { Block } \\
\text { Number }\end{array}$} & $\begin{array}{c}\text { Temperature } \\
\left({ }^{\circ} \mathrm{C}\right)\end{array}$ & $\begin{array}{c}\mathrm{P}_{\mathrm{H} 2} \\
(\mathrm{~Pa})\end{array}$ & $\begin{array}{c}\mathrm{P}_{\mathrm{H} 2 \mathrm{O}} \\
(\mathrm{Pa})\end{array}$ & $\begin{array}{l}\text { Time } \\
(\mathrm{h})\end{array}$ & $\begin{array}{c}\text { Weight } \\
\text { Loss } \\
(\%)\end{array}$ & $\begin{array}{c}\text { Oxidized Together } \\
\text { or Separately }\end{array}$ \\
\hline \multirow{2}{*}{1} & 900 & 4000 & 400 & 100 & 1.02 & Oxidized together \\
3 & 900 & 4000 & 400 & 100 & 0.34 & Oxidized together \\
7 & 900 & 4000 & 400 & 98 & 0.92 & Separate \\
8 & 900 & 4000 & 400 & 196 & 0.78 & Oxidized together \\
11 & 900 & 4000 & 400 & 196 & 2.52 & Oxidized together \\
12 & 900 & 4000 & 400 & 196 & 2.18 & Separate \\
\hline
\end{tabular}



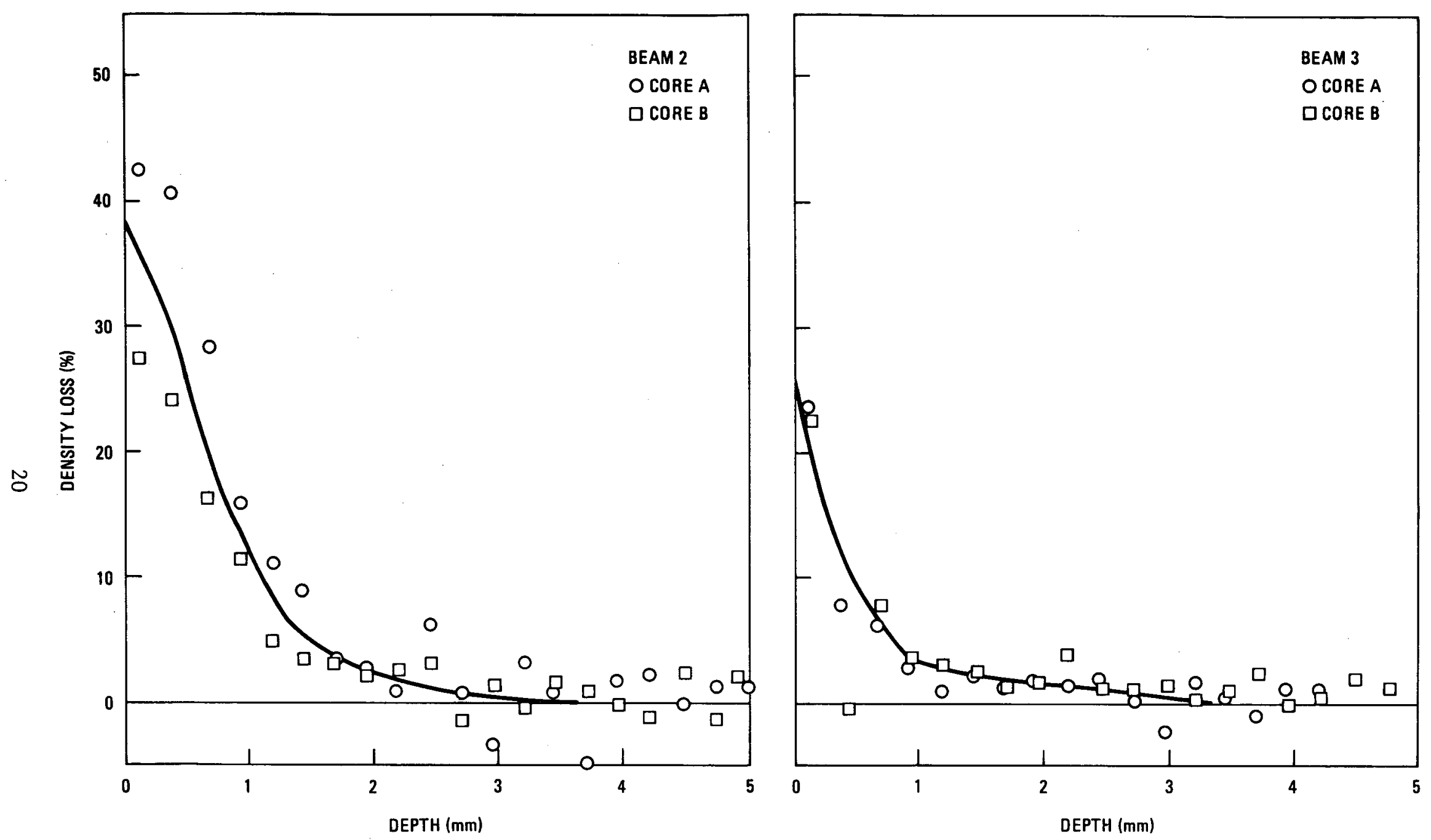

Fig. 10. Surface oxidation profile for PGX graphite, $\log 6484-112$, $\log 1$ 

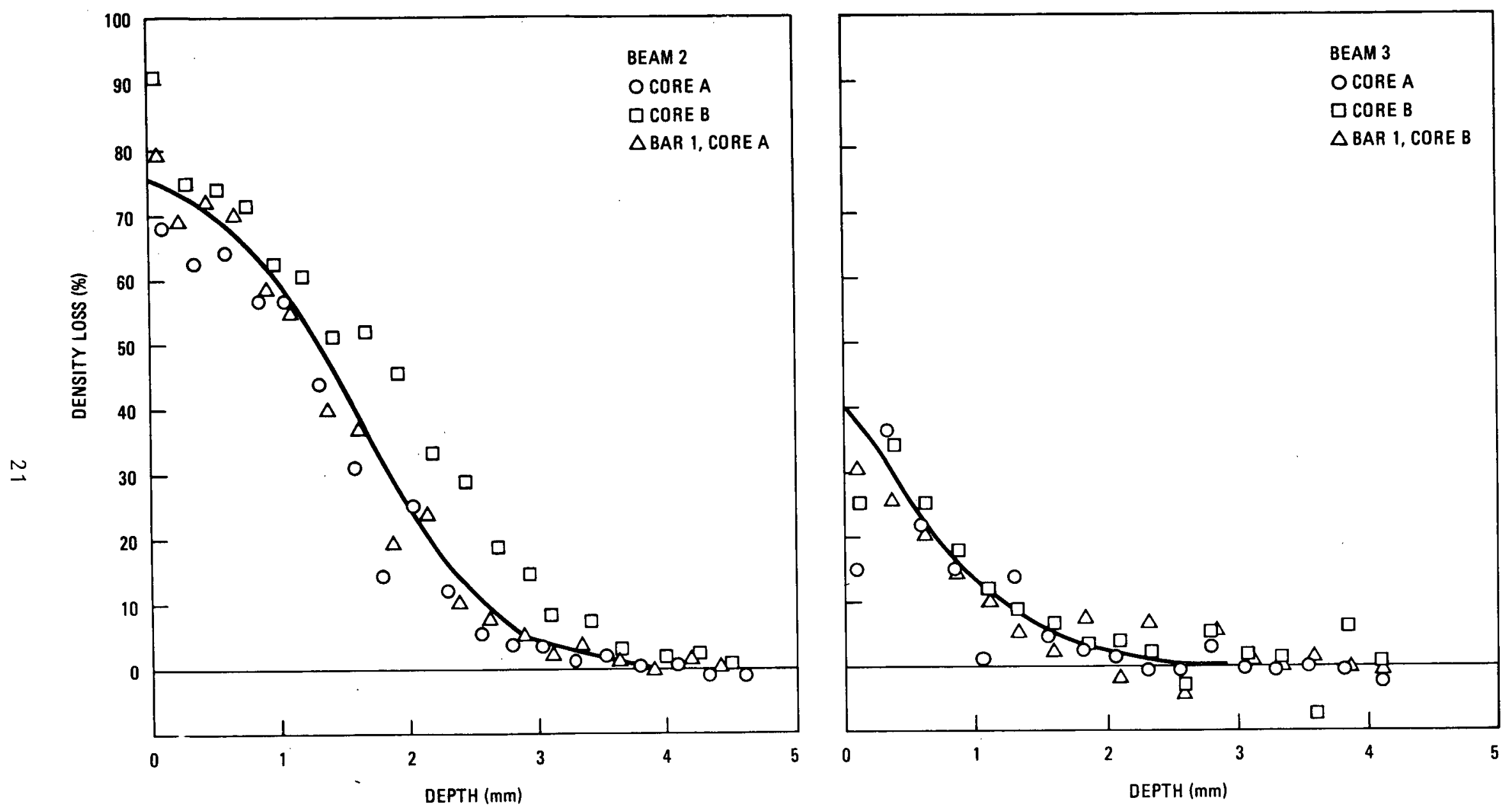

Fig. 11. Surface oxidation profile for PGX graphite, $\log 6484-112$, $\log 3$ 

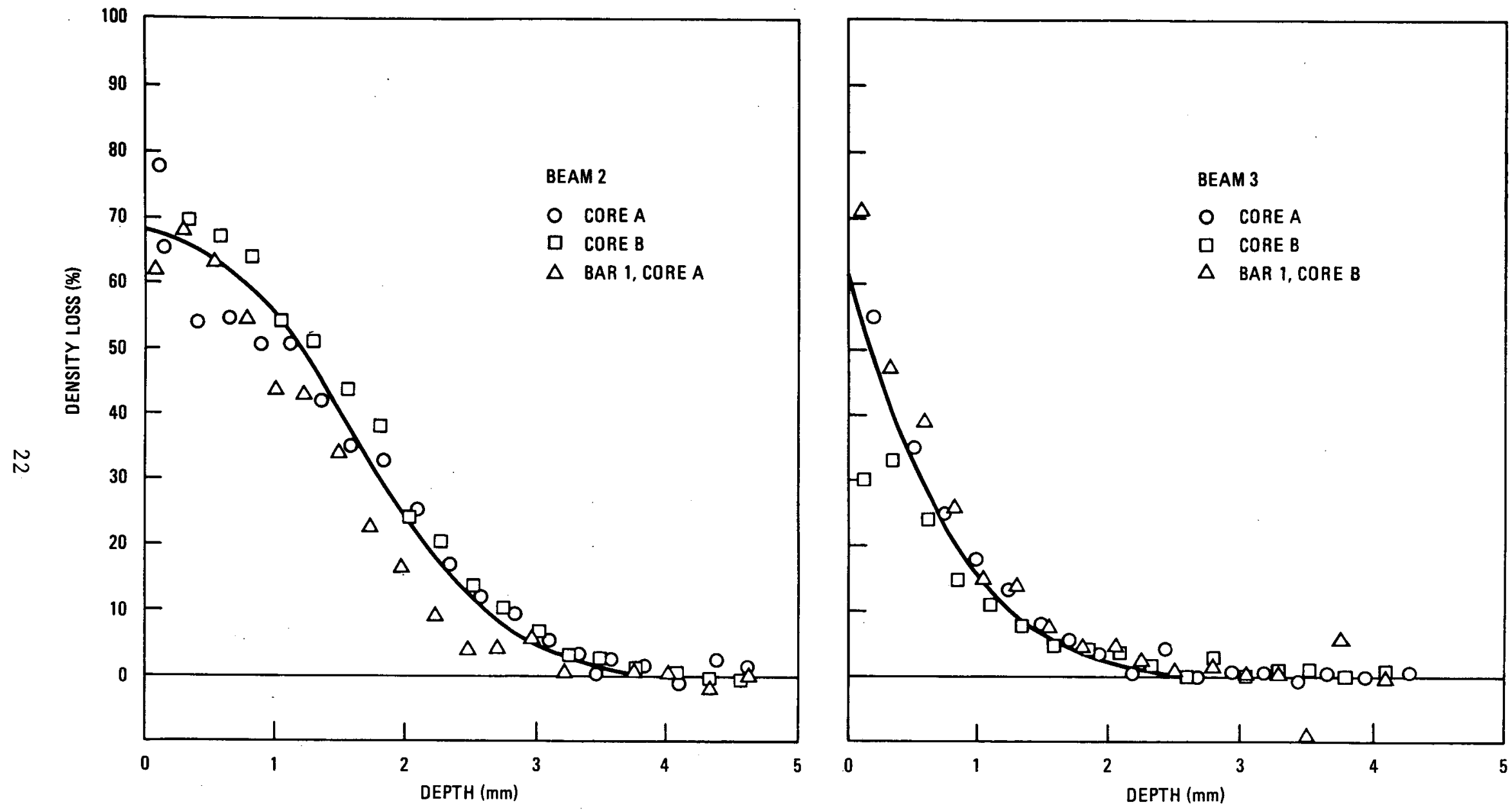

Fig. 12. Surface oxidation profile for PGX graphite, $\log 6484-112, \log 8$ 

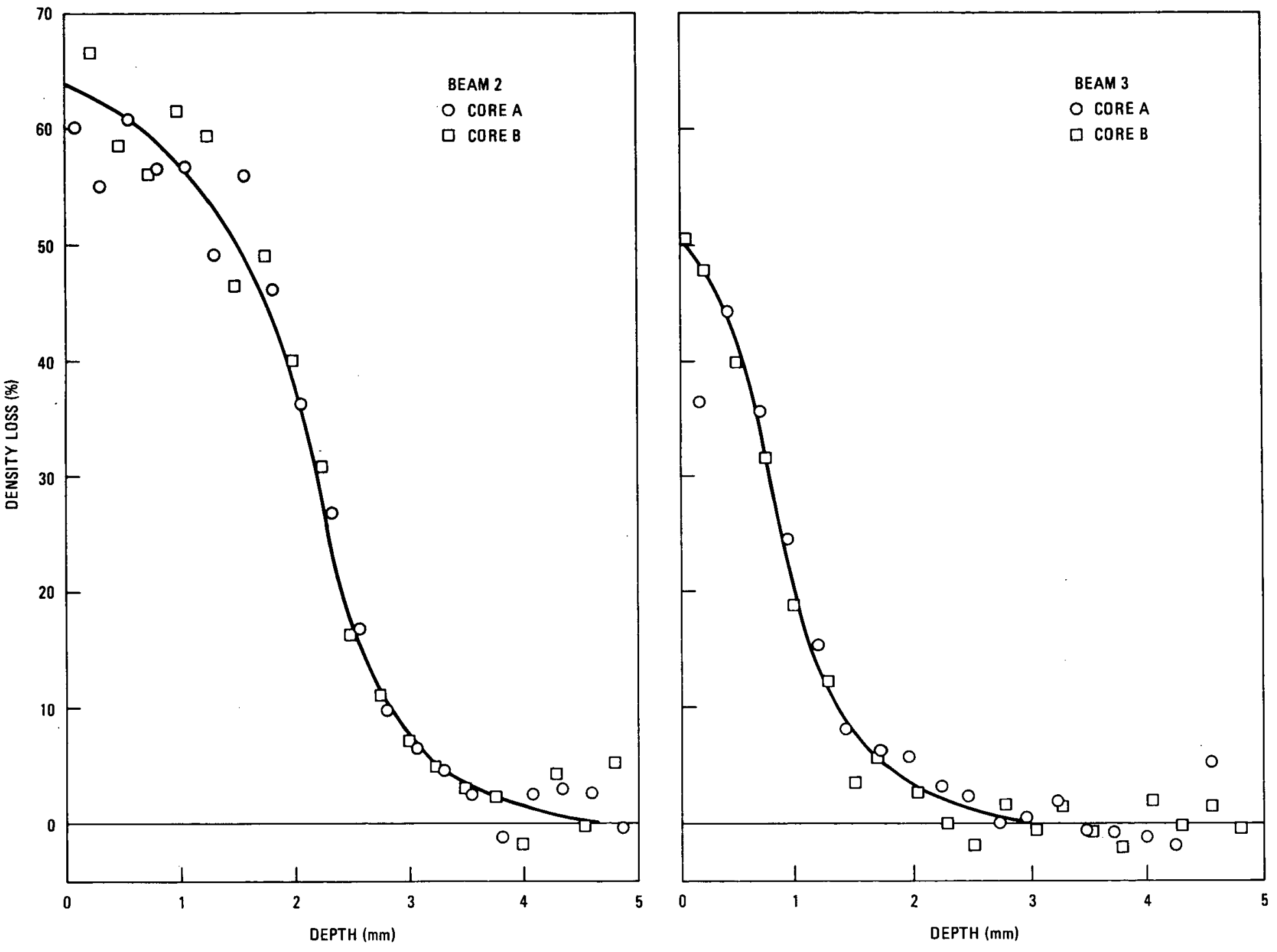

Fig. 13. Surface oxidation profile for PGX graphite, $\log 6484-112, \log 11$ 

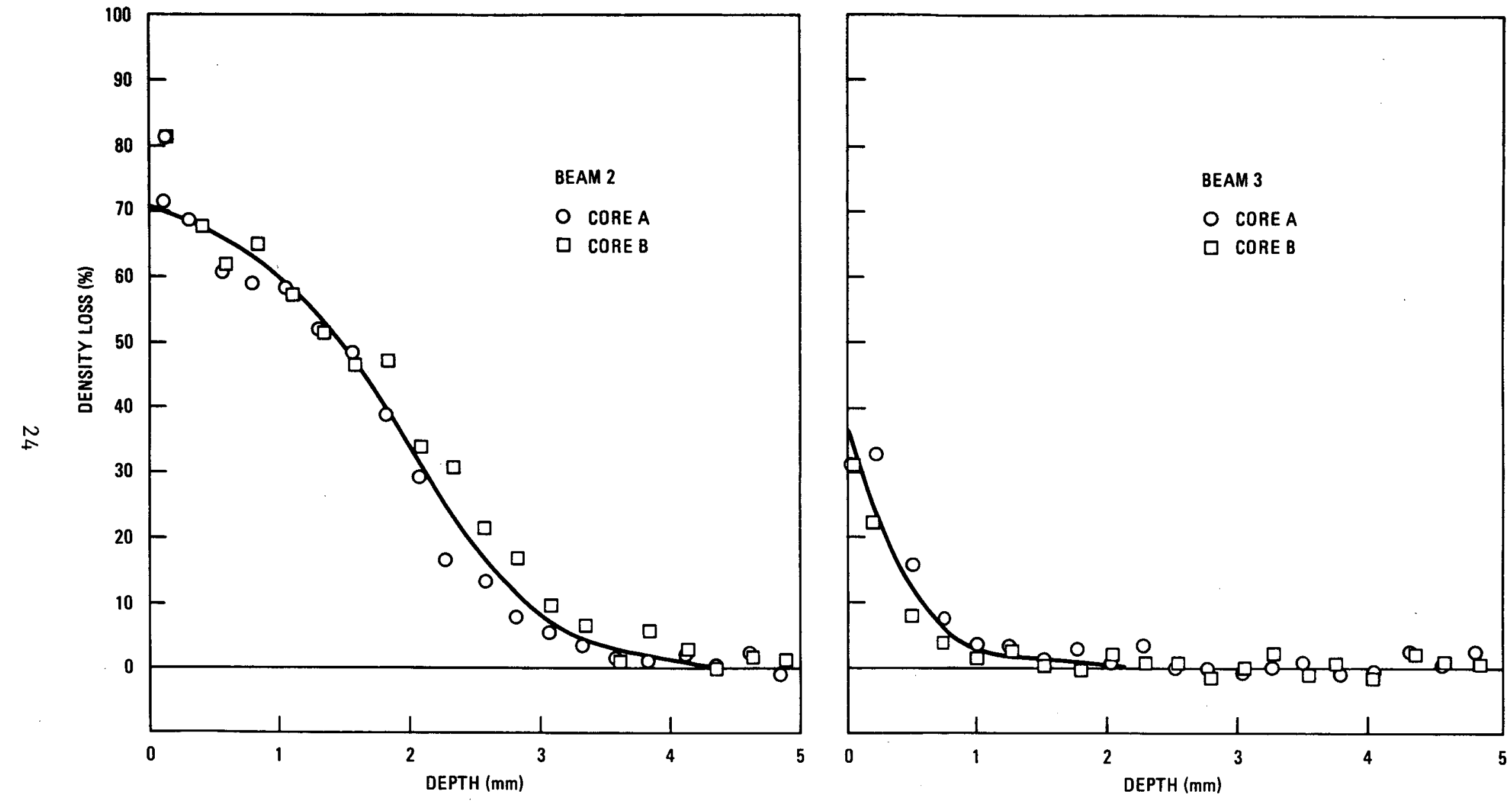

Fig. 14. Surface oxidation profile for PGX graphite, $\log 6484-112$, $\log 12$ 
TABLE 3

FLEXURAL PROPERTIES OF PGX GRAPHITE: UNOXIDIZED CONTROLS

\begin{tabular}{|c|c|c|}
\hline $\begin{array}{l}\text { Specimen } \\
\text { Number }\end{array}$ & $\begin{array}{l}\text { Center Point } \\
\text { Deflection } \\
(\mathrm{mm})\end{array}$ & $\begin{array}{l}\text { Modulus of } \\
\text { Rupture } \\
\text { (MPa) }\end{array}$ \\
\hline $2 \mathrm{~A}$ & 1.16 & 12.5 \\
\hline $2 B$ & 1.20 & 12.3 \\
\hline $6 \mathrm{~A}$ & 1.15 & 12.5 \\
\hline $6 \mathrm{~B}$ & 1.10 & 10.8 \\
\hline $20 \mathrm{~A}$ & 1.35 & 12.4 \\
\hline $20 \mathrm{~B}$ & 1.22 & 12.2 \\
\hline $22 \mathrm{~A}$ & 1.27 & 12.4 \\
\hline $22 \mathrm{~B}$ & 1.36 & 12.8 \\
\hline $26 \mathrm{~A}$ & 1.27 & 12.2 \\
\hline $26 \mathrm{~B}$ & 1.31 & 12.7 \\
\hline $9 \mathrm{~A}$ & 1.08 & 10.7 \\
\hline $9 B$ & 1.21 & 11.7 \\
\hline $13 \mathrm{~A}$ & 1.23 & 12.0 \\
\hline $13 B$ & 1.16 & 11.5 \\
\hline $17 \mathrm{~A}$ & 1.18 & 11.8 \\
\hline $17 \mathrm{~B}$ & 1.29 & 12.7 \\
\hline Mean & $\begin{array}{l}1.22 \\
(0.048 \text { in. })\end{array}$ & $\begin{array}{c}12.1 \\
(1752 \text { psi) }\end{array}$ \\
\hline $\begin{array}{l}\text { Standard } \\
\text { deviation }\end{array}$ & $\begin{array}{l}0.08 \\
(0.003 \text { in. })\end{array}$ & $\begin{array}{l}0.6 \\
\text { (90 psi) }\end{array}$ \\
\hline $\begin{array}{l}\text { Mean flexural } \\
\text { Young's modulus }\end{array}$ & & $\begin{array}{l}4.14 \mathrm{GPa} \\
\left(6.01 \times 10^{5} \mathrm{psi}\right)\end{array}$ \\
\hline $\begin{array}{l}\text { Standard } \\
\text { deviation }\end{array}$ & & $\begin{array}{l}0.18 \mathrm{GPa} \\
\left(0.26 \times 10^{5} \mathrm{psi}\right)\end{array}$ \\
\hline
\end{tabular}


Seven of the surface-oxidized beams were tested with their oxidized surface in tension, and three were tested with their oxidized surface in compression. The test data are listed in Table 4, and the modulus of rupture is plotted against burnoff depth in Fig. 15. The modulus of rupture decreased with burnoff depth, falling to about $70 \%$ of the unoxidized value for a $3 \mathrm{~mm}$ (0.12 in.) deep burnoff layer. There was little difference between beams tested with their oxidized surface in tension and those tested with the oxidized surface in compression. The apparent Young's modulus showed no systematic change with burnoff depth.

\subsection{NONUNIFORM OXIDATION: TENSILE TESTS}

Eight unoxidized control specimens were tensile tested to failure; the data are shown in Table 5. The mean tensile strength was $8.4 \mathrm{MPa}$ (1215 psi). Strains were not measured.

The tensile strength of five oxidized bars, one of which was tested a second time after re-cementing, are shown in Table 6 . Changes in tensile strength were much smaller than the changes in flexural strength; in fact, four of the six specimens broke in the unoxidized zone. Both unoxidized and oxidized specimens tended to break near (but not through) the cemented joint.. 
TABLE 4

FLEXURAL PROPERTIES OF SURFACE-OXIDIZED PGX GRAPHITE

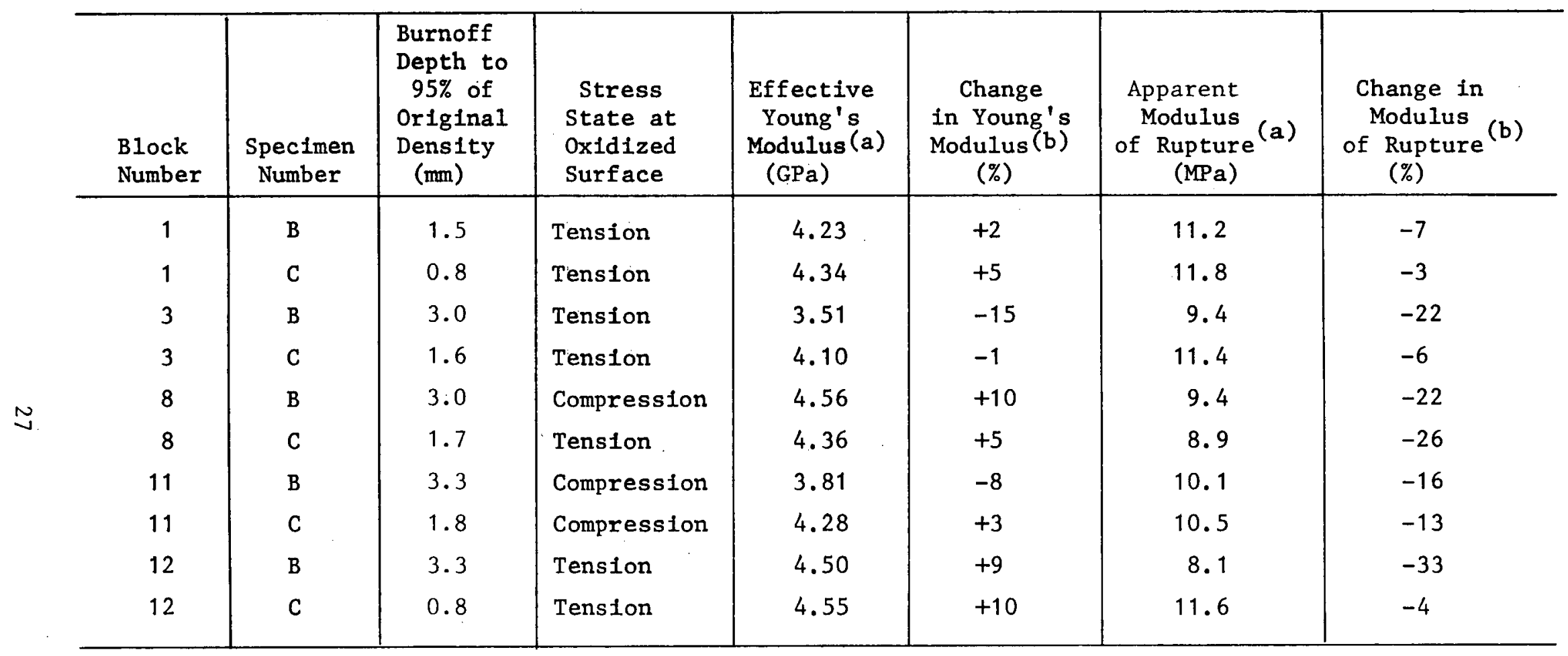

(a) Calculated assuming untform elastic properties.

(b) Compared with mean of 16 unoxidized controls. 


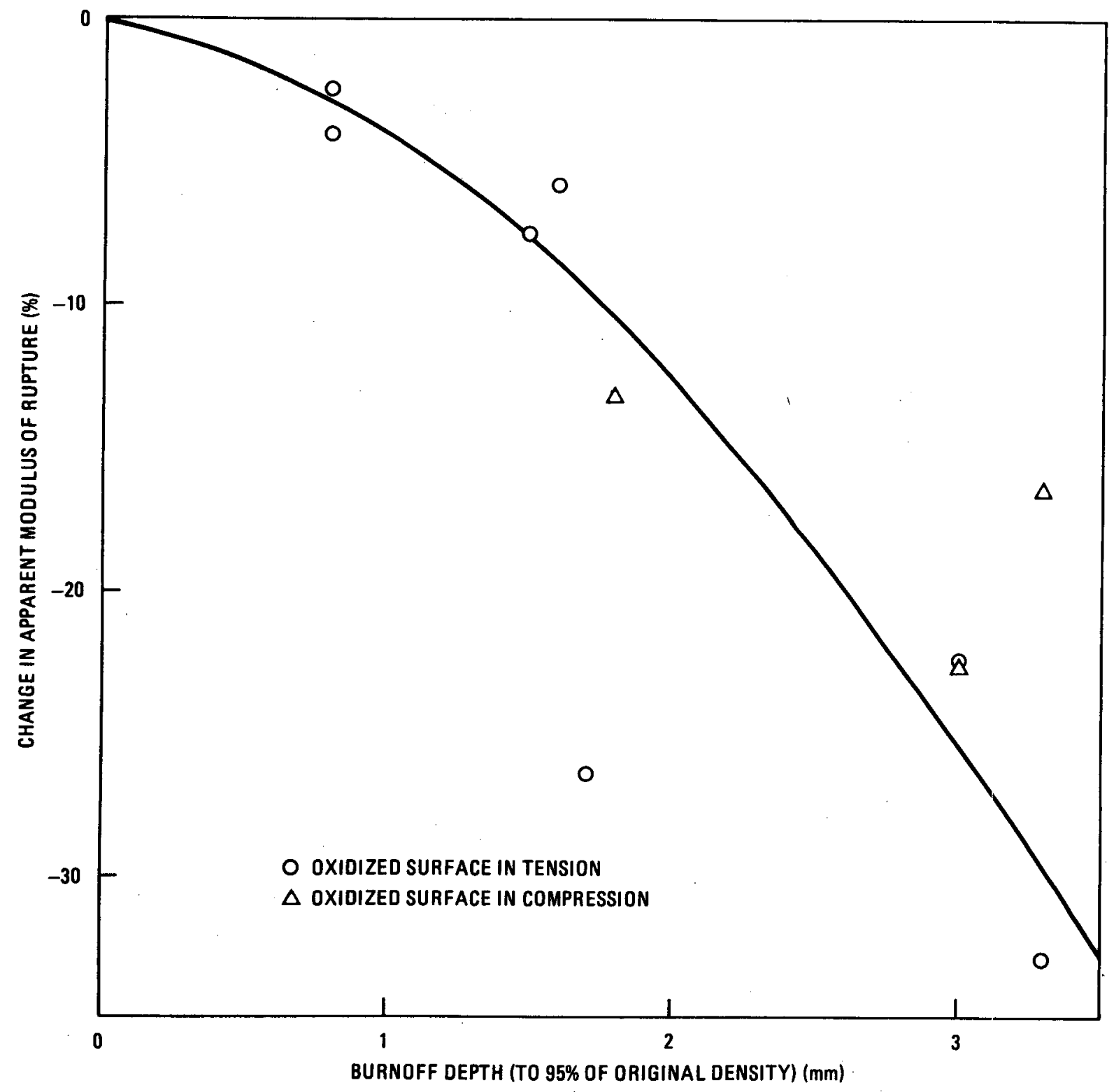

Fig. 15. Change in apparent modulus of rupture versus burnoff depth in surface-oxidized PGX graphite 
TABLE 5

TENSILE STRENGTH OF PGX GRAPHITE: UNOXIDIZED CONTROLS

\begin{tabular}{c|c}
\hline $\begin{array}{c}\text { Specimen } \\
\text { Number }\end{array}$ & $\begin{array}{c}\text { Tensile Strength } \\
(\mathrm{MPa})\end{array}$ \\
\hline 2 & 8.94 \\
6 & 6.39 \\
20 & 8.71 \\
22 & 8.40 \\
26 & 9.04 \\
9 & 8.54 \\
13 & 8.05 \\
17 & 8.93 \\
& $8.38 \mathrm{MPa}$ \\
Mean & $(1215 \mathrm{psi})$ \\
& $0.87 \mathrm{MPa}$ \\
Standard & $(126 \mathrm{psi})$ \\
\hline
\end{tabular}


TABLE 6

TENSILE STRENGTH OF SURFACE-OXIDIZED BARS OF PGX

\begin{tabular}{c|c|c|c}
\hline $\begin{array}{c}\text { Block } \\
\text { Number }\end{array}$ & $\begin{array}{c}\text { Overall Burnoff } \\
\text { in Parent Block } \\
(\%)\end{array}$ & $\begin{array}{c}\text { Fracture Location } \\
\text { with Respect to } \\
\text { Oxidized Zone }\end{array}$ & $\begin{array}{c}\text { Tensile Strength } \\
(\mathrm{MPa})\end{array}$ \\
\hline 1 & 1.02 & Outside & 6.8 \\
1 & 1.02 & Outside & 8.5 (retest) \\
3 & 0.34 & Inside & 7.4 \\
8 & 0.78 & Inside & 7.3 \\
11 & 2.52 & Outside & 8.0 \\
12 & 2.18 & Outside & 6.9 \\
\hline
\end{tabular}




\section{ANALYSIS}

\subsection{FLEXURAL TESTS}

The flexural tests were analyzed using a linear elastic model in which the Young's modulus of the material varies through the thickness of the beam. For a rectangular cross section beam of width $b$ and height $h$, Young's modulus of a strip of material a distance $x$ from the tensile surface is $E(x)$. Assuming linear elasticity and that plane cross sections remain plane, the requirement for zero net force acting on a cross section gives the following expression for the strain, $\varepsilon$, as a function of $\mathrm{x}$ :

$$
\varepsilon=\varepsilon_{0}\left(1-\frac{I_{0}}{I_{1}} x\right)
$$

where $\varepsilon_{0}$ is the strain at the tensile surface $(x=0)$ and $I_{0}$ and $I_{1}$ are the integrals, respectively, of Young's modulus and the first moment of Young's modulus across the beam:

$$
I_{0}=\int_{0}^{h} E(x) d x \text { and } I_{1}=\int_{0}^{h} x E(x) d x
$$

Equation 3 locates the neutral axis of the beam. Integrating the bending moments across the beam gives the following expression for total bending moment, M:

$$
M=b \varepsilon_{0}\left(I_{1}-\frac{I_{0} I_{2}}{I_{1}}\right),
$$


where $I_{2}$ is the second moment of Young's modulus integrated across the beam:

$$
I_{2}=\int_{0}^{h} x^{2} E(x) d x
$$

As discussed in Section 4.1, in the absence of gross oxidation gradients, oxidation reduces the strength and Young's modulus in the same proportion and the strain at failure remains almost unchanged. Failure of the oxidized beams will therefore be initiated when the strain at the tensile surface, $\varepsilon_{0}$, equals the unoxidized fracture strain. Using this failure criterion, the flexural strength, $S$, of an oxidized specimen is related to the flexural strength of an unoxidized specimen, $\mathrm{s}_{0}$, as follows:

$$
\frac{S}{S_{0}}=\frac{6\left(\frac{I_{0} I_{2}}{I_{1}}-I_{1}\right)}{E_{0} h^{2}} \text {, }
$$

where $E_{0}$ is Young's modulus of unoxidized material.

The decrease in Young's modulus in oxidized graphite free from gross oxidation gradients can be represented by Eqs. 1 or 2 (Section 4.1). For oxidation involving some local pitting, such as occurred during oxidation of the beams in the current study, an exponent of about 5 is appropriate; for more homogeneous oxidation, the exponent is about 10 (see Section 4.1). The integrals $I_{0}, I_{1}$, and $I_{2}$ can now be evaluated from the measured burnoff profiles, $y(x)$ :

$$
\begin{aligned}
& I_{0}=E_{0} \int_{0}^{h}[1-y(x)]^{m} d x \text { (Eq. 1) or } \quad E_{0} \int_{0}^{h} \exp [-m y(x)] d x \text { (Eq. 2) } \\
& I_{1}=E_{0} \int_{0}^{h} x[1-y(x)]^{m} d x(E q .1) \quad \text { or } \quad E_{0} \int_{0}^{h} x \exp [-m y(x)] d x \text { (Eq. 2) } \\
& I_{2}=E_{0} \int_{0}^{h} x^{2}[1-y(x)]^{m} d x(E q .1) \quad \text { or } \quad E_{0} \int_{0}^{h} x^{2} \exp [-m y(x)] d x \text { (Eq. 2) }
\end{aligned}
$$


The integrals in Eq. 6 can be calculated from the measured burnoff profiles by numerical integration. It is important to retain the convention that the lower integration limit is the tensile surface, regardless of whether this is the oxidized or unoxidized face.

The flexural specimens in the current study were tested in four-point bending with the support and loading points equally spaced $76 \mathrm{~mm}$ (3 in.) apart. Only the center span of the specimen was subjected to an oxidation profile; the outer spans consisted of unoxidized graphite. The center point deflection is controlled by the elastic properties of both the oxidized inner span and the unoxidized outer spans. The deflection of the inner loading points with respect to the outer support points, $\delta_{0}$, can be obtained from standard uniform beam theory:

$$
\delta_{0}=\frac{5 \mathrm{Sa}^{2}}{3 \mathrm{E}_{0} \mathrm{~h}}
$$

where $a$ is the distance separating a loading point from the closest support point. Substituting the value of $\mathrm{S}$ from Eq. 5, the expected deflection is:

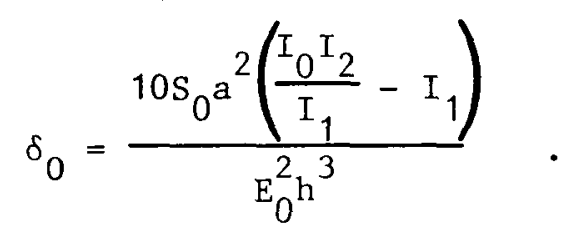

The deflection of the beam center point with respect to the loading points, $\delta_{1}$, is given by:

$$
\delta_{1}=\frac{a^{2} \varepsilon_{0}}{8 c}=\frac{a^{2} S_{0}}{8 E_{0} c}
$$


where $c$ is the distance of the neutral axis from the tensile surface and is equal to $I_{1} / I_{0}$. The total center point deflection, as measured in the experiments, is equal to $\delta_{0}+\delta_{1}$.

The measured oxidation profiles of ten tested beams were used to calculate $I_{0}, I_{1}$, and $I_{2}$ from Eq. 6, using a 100-step Simpson's rule numerical integration. Calculations were made for a burnoff exponent, $m$, of both 5 and 10. The predicted flexural strength and center point deflection were calculated from Eqs. 5, 8, and 9. The results of the calculations are shown in Table 7, together with the measured values. The calculated values in Table 7 assume the relationship of Eq. 1; calculations based on Eq. 2 differed by less than 1\% from the tabulated values. Figure 16 shows the observed flexural strength plotted against the predicted flexural strength for $m=5$. The predictions agree quite well with the observations. For beams tested with their oxidized surface in tension, the measured strengths tended to be slightly higher than predicted, while for the three beams tested with their oxidized surface in compression, the agreement between observations and predictions was very close. For $m=10$, the strengths are consistently underpredicted by the model. Figure 17 shows a comparison between observed and predicted center point deflections for $m=5$. Again, with the exception of one anomalous point, the agreement is good. The predicted deflections are insensitive to the value of $\mathrm{m}$.

\subsection{TENSILE TESTS}

The tensile tests were analyzed using the same model as was used for the flexural tests. In the tensile case the strain, $\varepsilon$, is uniform across the bar and the stress at a distance $x$ from the surface is $\varepsilon E(x)$. The total load, $P$, is given by:

$$
P=\varepsilon b \int_{0}^{h} E(x) d x=\varepsilon b I_{0},
$$


TABLE 7

COMPARISON OF OBSERVED AND CALCULATED

FLEXURAL BEHAVIOR OF SURFACE-OXIDIZED PGX GRAPHITE

\begin{tabular}{|c|c|c|c|c|c|c|c|c|c|}
\hline \multirow[b]{2}{*}{$\begin{array}{l}\text { Block } \\
\text { No. }\end{array}$} & \multirow[b]{2}{*}{$\begin{array}{c}\text { Specimen } \\
\text { No. }\end{array}$} & \multirow{2}{*}{$\begin{array}{l}\text { Burnoff } \\
\text { Depth } \\
\text { to } 95 \% \\
\text { Density } \\
\text { (mm) }\end{array}$} & \multirow{2}{*}{$\begin{array}{l}\text { Stress } \\
\text { State at } \\
\text { Oxidized } \\
\text { Surface }\end{array}$} & \multicolumn{3}{|c|}{$\begin{array}{c}\text { Flexural Strength } \\
(\mathrm{GPa})\end{array}$} & \multicolumn{3}{|c|}{ Maximum Deflection (mm) } \\
\hline & & & & $\begin{array}{c}\text { Experi- } \\
\text { mental }(a)\end{array}$ & $\begin{array}{l}\text { Calc. } \\
\text { for } m=5\end{array}$ & $\begin{array}{c}\text { Calc. } \\
\text { for } m=10\end{array}$ & $\begin{array}{l}\text { Experi- } \\
\text { mental }\end{array}$ & $\begin{array}{c}\mathrm{Ca} 1 \mathrm{c} . \\
\text { for } \mathrm{m}=5\end{array}$ & $\begin{array}{l}\text { Calc. } \\
\text { for } m=10\end{array}$ \\
\hline $\begin{array}{r}1 \\
1 \\
3 \\
3 \\
8 \\
8 \\
11 \\
11 \\
12 \\
12\end{array}$ & $\begin{array}{l}2 \\
3 \\
2 \\
3 \\
2 \\
3 \\
2 \\
3 \\
2 \\
3\end{array}$ & $\begin{array}{l}1.5 \\
0.8 \\
3.0 \\
1.6 \\
3.0 \\
1.7 \\
3.3 \\
1.8 \\
3.3 \\
0.8\end{array}$ & $\begin{array}{c}\text { Tension } \\
\text { Tension } \\
\text { Tension } \\
\text { Tension } \\
\text { Compression } \\
\text { Tension } \\
\text { Compression } \\
\text { Compression } \\
\text { Tension } \\
\text { Tension }\end{array}$ & $\begin{array}{r}11.2 \\
11.8 \\
9.4 \\
11.4 \\
9.4 \\
8.9 \\
10.1 \\
10.5 \\
8.1 \\
11.6\end{array}$ & $\begin{array}{r}10.2 \\
11.1 \\
7.8 \\
10.2 \\
9.5 \\
10.0 \\
9.5 \\
10.8 \\
7.5 \\
11.0\end{array}$ & $\begin{array}{r}9.5 \\
10.5 \\
7.2 \\
9.6 \\
9.1 \\
9.4 \\
9.2 \\
10.5 \\
7.0 \\
10.6\end{array}$ & $\begin{array}{l}1.20 \\
1.23 \\
1.32 \\
1.23 \\
1.08 \\
0.91 \\
1.22 \\
1.12 \\
0.83 \\
1.16\end{array}$ & $\begin{array}{l}1.11 \\
1.19 \\
0.88 \\
1.10 \\
1.10 \\
1.08 \\
1.07 \\
1.18 \\
0.85 \\
1.19\end{array}$ & $\begin{array}{l}1.04 \\
1.13 \\
0.85 \\
1.04 \\
1.07 \\
1.03 \\
1.04 \\
1.15 \\
0.80 \\
1.14\end{array}$ \\
\hline
\end{tabular}

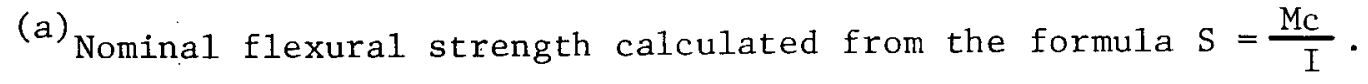




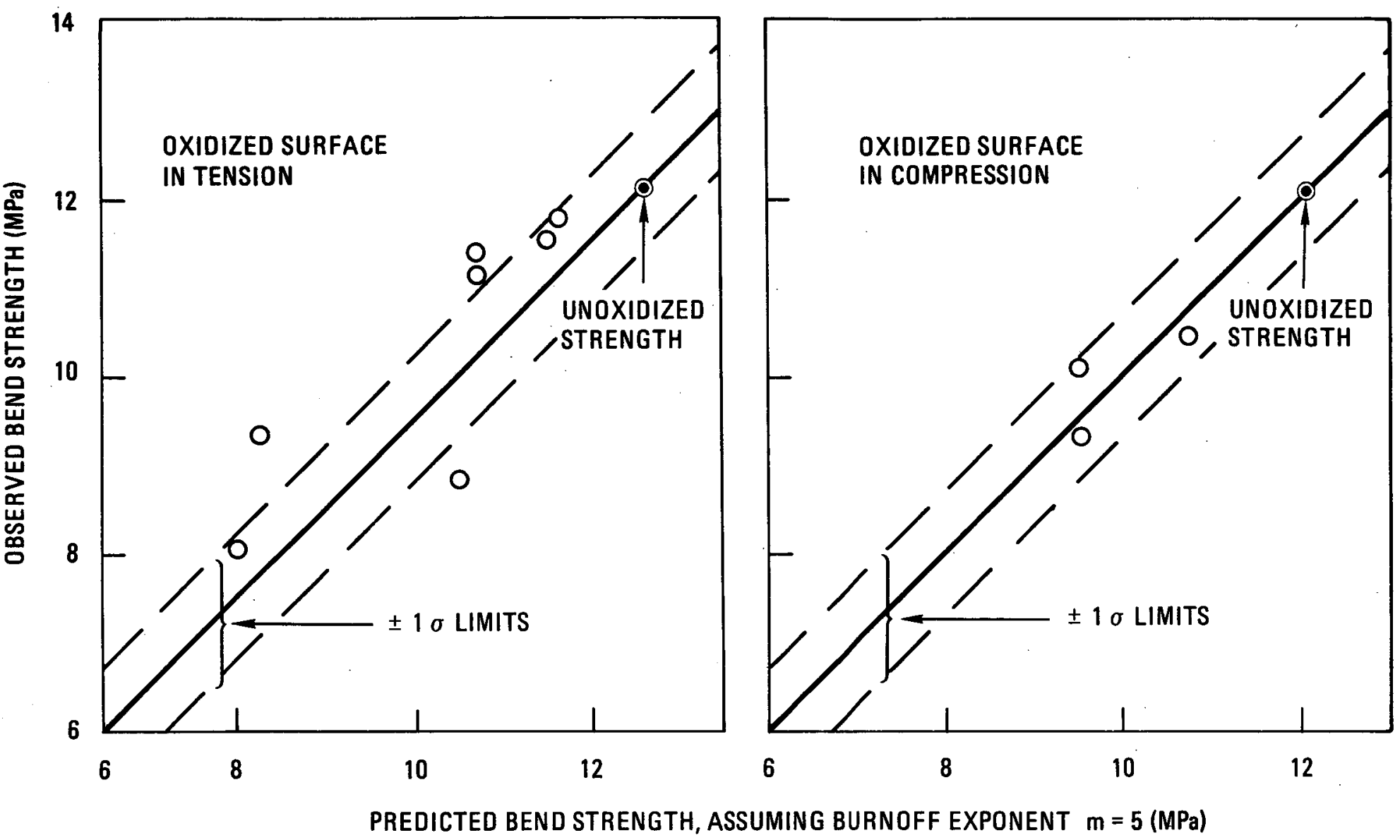

Fig. 16. Observed flexural strength versus predicted flexural strength for surface-oxidized PGX graphite 


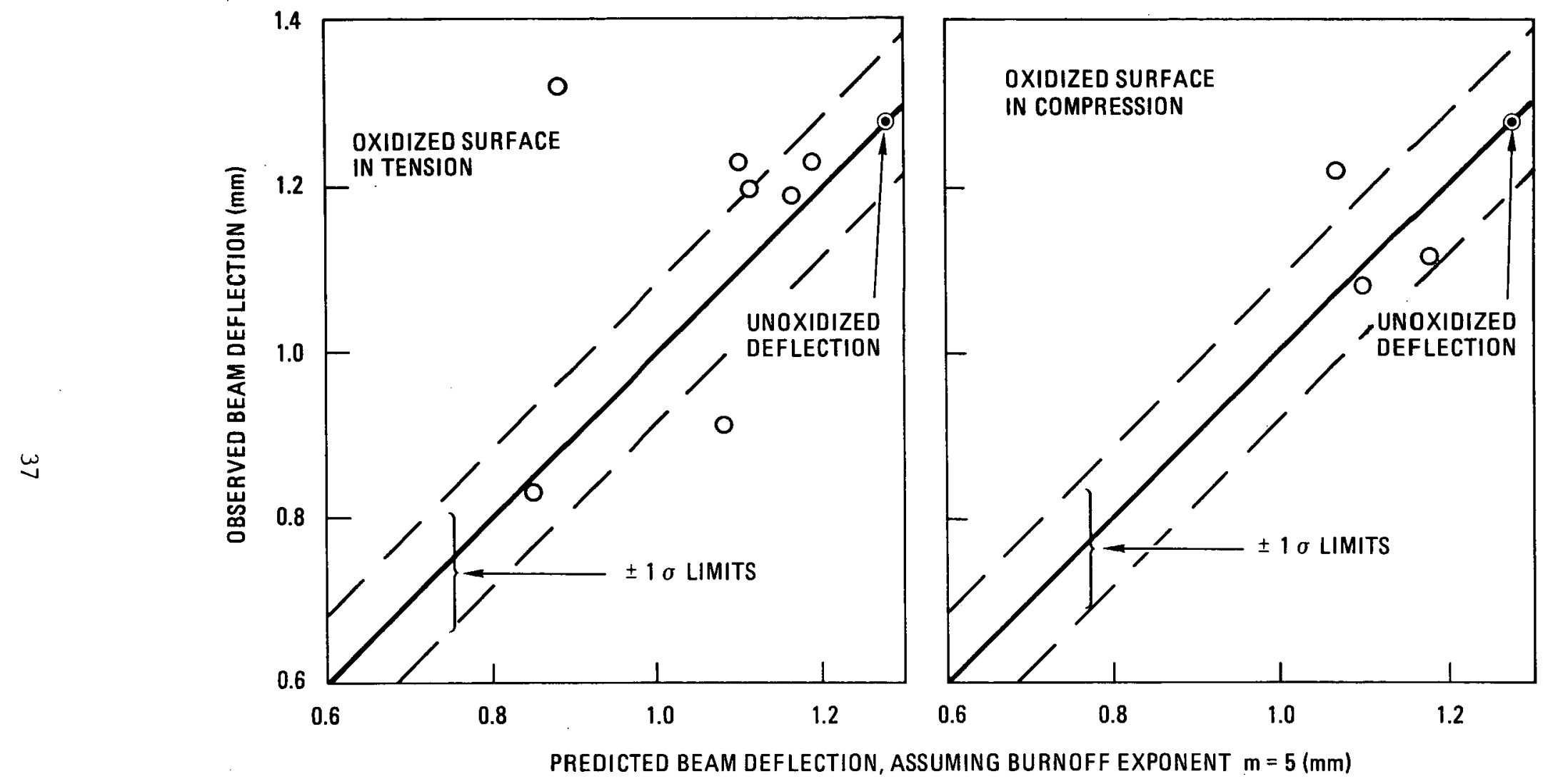

Fig. 17. Observed beam deflection versus predicted beam deflection for surface-oxidized PGX graphite 
using the same notation as in the previous section. The nominal tensile stress, $\sigma$, is given by:

$$
\sigma=\frac{\varepsilon I_{0}}{h}
$$

If it is assumed that the fracture strain is unaffected by oxidation, the strength, $S$, is related to the tensile strength of unoxidized material, $\mathrm{s}_{0}$, as follows:

$$
s=s_{0} \frac{I_{0}}{E_{0} h} .
$$

The integral, $I_{0}$, was calculated from the oxidation profile for each tensile bar, and the predicted strength was calculated from Eq. 12, using a strength reduction exponent, $\mathrm{m}$, of 5 or 1.0 . The calculated and observed strengths are listed in Table 8 and plotted in Fig. 18. The calculated values are insensitive to $\mathrm{m}$ or to the form of the strength reduction equation (Eq. 1 or 2). The observed tensile strengths fall within one standard deviation of the predicted strengths (Fig. 18); however, the fractional reduction in tensile strength is small (compared to the reduction in flexural strength) and the data scatter is higher. Thus, the tensile strength measurements are not a very sensitive test of the model. The fact that three of the five specimens broke outside the oxidized zone shows that the weakening effect of parasitic stress concentrations exceeds that of the surface-oxidized zone. 
TABLE 8

COMPARISON OF OBSERVED AND CALCULATED

TENSILE STRENGTH OF SURFACE-OXIDIZED PGX GRAPHITE

\begin{tabular}{c|c|c|c}
\hline \multirow{2}{*}{$\begin{array}{c}\text { Block } \\
\text { Number }\end{array}$} & Observed & $\begin{array}{c}\text { Talculated } \\
\text { for m }=5\end{array}$ & $\begin{array}{c}\text { Calculàted } \\
\text { for m = 10 }\end{array}$ \\
\cline { 2 - 4 } & 8.5 & 8.1 & 8.0 \\
3 & 7.4 & 7.7 & 7.6 \\
8 & 7.3 & 7.8 & 7.6 \\
11 & 8.0 & 7.7 & 7.6 \\
12 & 6.9 & 8.0 & 7.7 \\
\hline
\end{tabular}




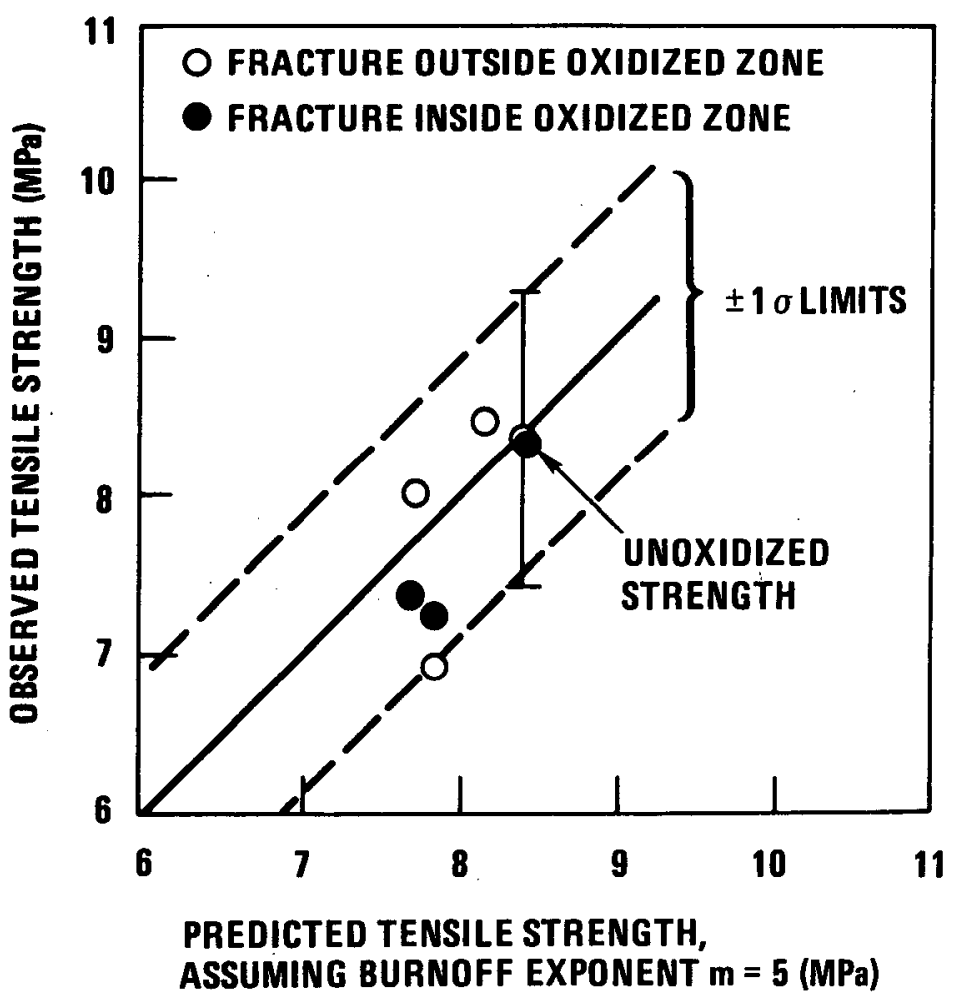

Fig. 18. Observed tensile strength versus predicted tensile strength for surface-oxidized PGX graphite 


\section{SUMMARY AND CONCLUSIONS}

Flexura1 and tensile tests were performed on PGX graphite oxidized to produce a steep surface oxidation gradient. The oxidation profiles were measured after strength testing. Companion tensile specimens were oxidized (under different conditions) to produce uniform oxidation throughout the specimen, and their tenstle strength and Young's modulus were measured.

The uniform oxidation tests confirmed earlier work which showed that oxidation sharply reduces the strength, S, and Young's modulus, E, in about the same proportion, while leaving the strain to failure almost unchanged. The strength reduction, as a function of the fractional burnoff, y, can be represented either by the equation

$$
\frac{\mathrm{S}}{\mathrm{S}_{0}}=\frac{\mathrm{E}}{\mathrm{E}_{0}}=(1-\mathrm{y})^{\mathrm{m}}
$$

or by the equation

$$
\frac{\mathrm{S}}{\mathrm{S}_{0}}=\frac{\mathrm{E}}{\mathrm{E}_{0}}=\exp (-\mathrm{my})
$$

The exponent, $\mathrm{m}$, has a value between 4 and 12 and depends on the morphology of the oxidation-induced porosity.

In contrast with the rapid decline in strength and modulus resulting from uniform burnoff, the effects of surface oxidation are much less severe. With an oxidized zone (defined as the zone where the local density is less than $95 \%$ of the original density) penetrating to about $13 \%$ of the specimen 
thickness, the flexural strength was reduced by about $30 \%$ and the tensile strength by about $12 \%$. The effective flexural elastic modulus was almost unchanged. Similar reductions in flexural strength were seen with the oxidized surface in tension or in compression.

The tests were analyzed according to a simple linear elastic model in which the local Young's modulus is a function of the oxidation state and the strain at failure is independent of oxidation. Measured oxidation profiles were used to predict flexural strength, beam deflection, and tensile strength. With a strength reduction exponent, $\mathrm{m}$, of 5 , the mode1 predictions agreed well with the measurements. With $\mathrm{m}=10$, the predicted strengths were lower than the observed strengths. The form of the strength reduction equation had very little effect on the calculated strengths because the oxidized zone carries very little load.

It is concluded that the strength of surface-oxidized PGX graphite can be quantitatively predicted from an elastic model in which Young's modulus is a function of the local burnoff. The strength of the unoxidized interior remains unaffected. There is no evidence that cracks originating in the oxidized surface layer cause unexpected weakening of the structure by propagating into the interior. 
REFERENCES

1. Burnette, R. D., C. Velasquez, and R. O. Harrington, "Studies of the Rate of Steam Oxidation of Graphite at High Velocity," Extended Abstracts of the 14th Biennial Conference on Carbon, American Carbon Society, 1979, p. 443.

2. Collins, A. C., H. G. Masterson, and P. P. Jennings, "The Effect of Oxidation on the Compressive Strength of Graphite," J. Nucl. Mater. 15, 135 (1965).

3. Board, J. A., and R. L. Squires, "The Effect of Oxidation in $\mathrm{CO}_{2}$ on Graphite Strength," Second Conference on Industrial Carbon and Graphite, Society of Chemical Industry, London, 1966, p. 289.

4. Rounthwaite, C., G. A. Lyons, and R. A. Snowdon, "Influence of Thermal Corrosion on the Strength, Permeability, and Frictional Properties of Nuclear Graphite," ibid., p. 299.

5. Hawkins, N., "Effect of Radiolytic Corrosion on the Mechanical Properties of Graphite," ibid., p. 355.

6. Knibbs, R. H., and J. B. Morris, "Some Effects of Oxidation on the Properties of Graphite," Third Conference on Industrial Carbon and Graphite, Society of Chemical Industry, London, 1971, p. 297.

7. Thrower, P. A., and J. C. Bognet, "The Effect of Oxidation on the Compression Strength of Graphite," Extended Abstracts of the 13th Biennial Conference on Carbon, American Carbon Society, 1977, p. 265.

8. Engle, G. B., and L. A. Beavan, "Properties of Unirradiated Graphites PGX, HLM and 2020 for Support and Permanent Side Reflector LHTGR Components," DOE Report GA-A14646, General Atomic Company, June 1978. 